\title{
Elevated NADPH oxidase activity contributes to oxidative stress and cell death in Huntington's disease
}

\author{
Antonio Valencia1, Ellen Sapp', Jeffrey S. Kimm¹, Hollis McClory', Patrick B. Reeves ${ }^{1}$, Jonathan \\ Alexander ${ }^{1}$, Kwadwo A. Ansong1, Nicholas Masso', Matthew P. Frosch², Kimberly B. Kegel' ${ }^{1}$, \\ Xueyi $\mathrm{Li}^{1}$ and Marian DiFiglia',* \\ ${ }^{1}$ Department of Neurology, Massachusetts General Hospital and Harvard Medical School, 114 16th Street, \\ Charlestown, MA 02129, USA and ${ }^{2}$ C.S. Kubik Laboratory for Neuropathology, Pathology Service, Massachusetts \\ General Hospital and Harvard Medical School, 55 Fruit Street, Boston, MA 02114, USA
}

Received October 11, 2012; Revised November 21, 2012; Accepted December 3, 2012

A mutation in the huntingtin (Htt) gene produces mutant Htt and Huntington's disease (HD), a neurodegenerative disorder. HD patients have oxidative damage in the brain, but the causes are unclear. Compared with controls, we found brain levels of NADPH oxidase (NOX) activity, which produces reactive oxygen species (ROS), elevated in human HD postmortem cortex and striatum and highest in striatum of presymptomatic individuals. Synaptosome fractions from cortex and striatum of $\mathrm{HD}^{140 Q / 140 Q}$ mice had elevated NOX activity at 3 months of age and a further rise at 6 and 12 months compared with synaptosomes of age-matched wild-type (WT) mice. High NOX activity in primary cortical and striatal neurons of $\mathrm{HD}^{140 \mathrm{Q} / 140 \mathrm{Q}}$ mice correlated with more ROS and neurite swellings. These features and neuronal cell death were markedly reduced by treatment with NOX inhibitors such as diphenyleneiodonium (DPI), apocynin (APO) and VAS2870. The rise in ROS levels in mitochondria of $\mathrm{HD}^{140 \mathrm{Q} / 140 \mathrm{Q}}$ neurons followed the rise in NOX activity and inhibiting only mitochondrial ROS was not neuroprotective. Mutant Htt colocalized at plasma membrane lipid rafts with gp91-phox, a catalytic subunit for the NOX2 isoform. Assembly of NOX2 components at lipid rafts requires activation of Rac1 which was also elevated in $\mathrm{HD}^{140 \mathrm{Q} / 140 Q}$ neurons. $\mathrm{HD}^{140 \mathrm{Q} / 140 Q}$ mice bred to gp91-phox knock-out mice had lower NOX activity in the brain and in primary neurons, and neurons had normal ROS levels and significantly improved survival. These findings suggest that increased NOX2 activity at lipid rafts is an early and major source of oxidative stress and cell death in $\mathrm{HD}^{140 \mathrm{Q} / 140 \mathrm{Q}}$ neurons.

\section{INTRODUCTION}

Oxidative stress in cells occurs if there is an excess of reactive oxygen species (ROS) levels or a deficient antioxidant capacity, or both; in neurons, oxidative stress causes morphological abnormalities and death (1). An expanded tract of polyglutamines in huntingtin (Htt) causes Huntington's disease (HD). HD patients' brain and peripheral blood show signs of oxidative damage $(2-6)$ as do tissues from animal models of HD $(7,8)$. In HD mice (R6/2 model), increases in striatal lipid peroxidation parallel the progression of neurological phenotypes (9), and evidence of DNA damage is detected in the urine, plasma and striatal microdialysates (10). Antioxidant treatments in HD transgenic mice reduce protein aggregates and improve motor performance $(11,12)$. However, the treatment of oxidative stress in HD patients has not been very effective to date (13). Mitochondria dysfunction may be a source of ROS overproduction in neurons in advanced HD but not in early stages of disease $(14,15)$. Therefore, study of other potential sources of oxidative stress in HD neurons is needed.

Nicotinamide adenine dinucleotide phosphate (NADPH) oxidase (NOX) generates ROS by catalyzing superoxide production through an electron transfer from NADPH to

\footnotetext{
${ }^{*}$ To whom correspondence should be addressed at: Department of Neurology, Massachusetts General Hospital East, 114, 16th Street, Room 2002, Charlestown, MA 02129, USA. Tel: +1 6177268446; Fax: +1 6177261264; Email: difiglia@helix.mgh.harvard.edu
} 
molecular oxygen (16). $\mathrm{H}_{2} \mathrm{O}_{2}$ is also formed as a by-product of NOX activity. There are five NOX genes (NOX1-5). NOX2 is present in the brain and in neurons and consists of two membrane subunits gp91-phox and p22-phox which form the catalytic core, cytosolic components p67-phox, p47-phox and p40-phox, and GTPase Rac (17). The orientation of NOX2 complex in the plasma membrane results in production of superoxide and subsequently hydrogen peroxide in the extracellular space. It is speculated that the superoxide anion can enter the cell through anion channels and hydrogen peroxide diffuses through the plasma membrane (reviewed in Fig. 5 in 18).

Human phagocytic cells are major NOX-dependent ROS producers and have been widely used for understanding functions of NOX $(19,20)$. Studies in phagocytic cells suggest that superoxide production upon activation of NOX2 occurs within the lumen of intracellular bodies containing the infectious pathogen (reviewed in 21). However, in non-phagocytic cells, including neurons, the distribution of NOX2 is mostly in plasma membrane lipid rafts which are domains important for cell signaling $(20,22-24)$. A host of functional and harmful roles of NOX2 in neurons have been observed. The production of hydrogen peroxide from NOX2 activity modulates neuronal differentiation and neurite outgrowth induced by NGF stimulation (25-27). ROS generated from NOX activity causes membrane potential changes through the production of a proton gradient and results in $\mathrm{pH}$ homeostasis and regulation of action potentials in hippocampal neurons (28). Exposure to ketamine, an NMDA receptor antagonist, stimulates NOX activity and ROS production and results in glutamate release and behavioral alterations (22). Interleukin-6 activates NOX2 and causes GABAergic neuronal degeneration and cognitive impairment in aged mice (29). NMDA receptor activation in hippocampal neurons generates superoxide radicals from NOX activity and if cortical neurons are exposed to excess glutamate, NOX activity increases and leads to cell death $(30,31)$. An increase in NOX2 activity has been implicated in different models of neurological disorders (32-40) and following ischemic insult is a source of oxidative damage to proteins in the postsynaptic density (36).

There is some support that ROS generated by NOX activity could play a role in the pathogenesis of HD. Elevated ROS levels in PC12 cells expressing an expanded polyglutamine peptide were lowered by treatment with inhibitors (40). NOX2 protein complex assembly and activation occurs at plasma membrane lipid rafts. Since mutant Htt localizes to plasma membrane lipid rafts in HD neurons (15), we speculated that lipid rafts might be the site where mutant Htt affects NOX2 activity. In this study, we investigate the role of NOX2 as a source of elevated ROS and neuronal cell death in human and mouse $\mathrm{HD}^{140 \mathrm{Q} / 140 \mathrm{Q}}$ brain. Our findings suggest that increased NOX2 activity in the early presymptomatic stage of HD is a major source of elevated ROS that contributes to oxidative damage at synaptic membranes and that leads to neuronal death.

\section{RESULTS}

NOX activity is increased in human and mouse HD brain and $\mathrm{HD}^{140 Q / 140 Q}$ mouse primary neurons

We examined NOX activity in human brain lysates of control and HD postmortem tissue using the method described by
Shpungin et al. (41; see Materials and Methods). Results showed that NOX activity was significantly increased in postmortem human HD cortex and striatum compared with control cortex and striatum (Fig. 1A). The postmortem cortex from two presymptomatic HD patient samples had higher levels of NOX activity than the adult onset HD samples (Fig. 1A, right-side graph). We also examined NOX activity in mouse brain. To enrich for synaptic membranes, we used a synaptosomal fraction (see Materials and Methods). NOX activity was significantly elevated in $\mathrm{HD}^{140 \mathrm{Q} / 140 \mathrm{Q}}$ cortical and striatal synaptosomes compared with WT synaptosomes at 3,6 and 12 months (Fig. 1B). In $\mathrm{HD}^{140 \mathrm{Q} / 140 \mathrm{Q}}$ synaptosomes, NOX activity levels increased markedly from 3 to 6 months. The highest levels of NOX activity occurred in the striata of 6-month-old $\mathrm{HD}^{140 \mathrm{Q} / 140 \mathrm{Q}}$ mice where the levels were 2.5 -fold greater than the levels in WT. The NOX activity levels at 12 months remained high in the cortex but declined in striatum compared with the levels at 6 months. The decline in striatum in 12-month-old mice may reflect a loss of synapses at this age. Striatal neuropathology in the $\mathrm{HD}^{140 \mathrm{Q} / 140 \mathrm{Q}}$ mice is detected at 6 months of age and increases with age $(42,43)$. We see a marked decline in the levels of synaptic proteins including SNAP-25 in striatal synaptosomes of $\mathrm{HD}^{140 \mathrm{Q} / 140 \mathrm{Q}}$ mice between 6 and 12 months of age (Valencia and DiFiglia, unpublished data). Thus in $\mathrm{HD}^{140 \mathrm{Q} / 140 \mathrm{Q}}$ brain, high levels of NOX activity occur in synaptic membrane-enriched compartments of regions known to be affected early in disease.

Next, we examined NOX activity in cultures of primary neurons at day 8 in vitro (DIV), a time when we have observed increased ROS levels in $\mathrm{HD}^{140 \mathrm{Q} / 140 \mathrm{Q}}$ primary cortical neurons compared with WT neurons $(44,45)$ but no cell death. There was significantly more NOX activity $(\sim 2$-fold $)$ in $\mathrm{HD}^{140 \mathrm{Q} / 140 \mathrm{Q}}$ primary neurons derived from embryonic cortex and neonatal striatum than in WT neurons obtained from corresponding regions (Fig. 1C). We treated neurons with inhibitors of NOX activity that are not selective for NOX isoforms. Apocynin (APO) prevents the assembly of NOX subunits and diphenyleneiodonium (DPI) competitively blocks the catalytic subunit $(46,47)$. Treating $\mathrm{HD}^{140 \mathrm{Q} / 140 \mathrm{Q}}$ neurons with APO and DPI reduced enzyme activity to the levels of WT neurons (Fig. 1C), whereas NOX activity in WT neurons was unaffected by APO and DPI treatment (Fig. 1D). The results are consistent with the role of a NOX enzyme in causing elevated ROS in $\mathrm{HD}^{140 \mathrm{Q} / 140 \mathrm{Q}}$ primary cortical and striatal neurons but do not prove it or identify the isoform that might be involved.

\section{$\mathrm{HD}^{140 \mathrm{Q} / 140 \mathrm{Q}}$ primary cortical and striatal neurons have elevated ROS levels in cell bodies and neurites compared with WT neurons}

ROS levels are markedly elevated in the cell bodies and neurites of primary cortical neurons of $\mathrm{HD}^{140 \mathrm{Q} / 140 \mathrm{Q}}$ embryonic mice at 8 DIV $(44,45)$. To determine whether primary neurons from neonatal $\mathrm{HD}^{140 \mathrm{Q} / 140 \mathrm{Q}}$ striata also had elevated levels of ROS, we exposed living primary cortical and striatal neurons at 8 DIV to 5-(and-6)-carboxy-2', $7^{\prime}$-dichlorofluorescein (DCF) diacetate (carboxy-DCFDA). The intensity of DCF fluorescence generated from carboxy-DCFDA is proportional to the amount of ROS in cells (48-51). The DCF signal was distributed diffusely throughout cell bodies and neurites of $\mathrm{WT}$ and $\mathrm{HD}^{140 \mathrm{Q} / 140 \mathrm{Q}}$ cortical 


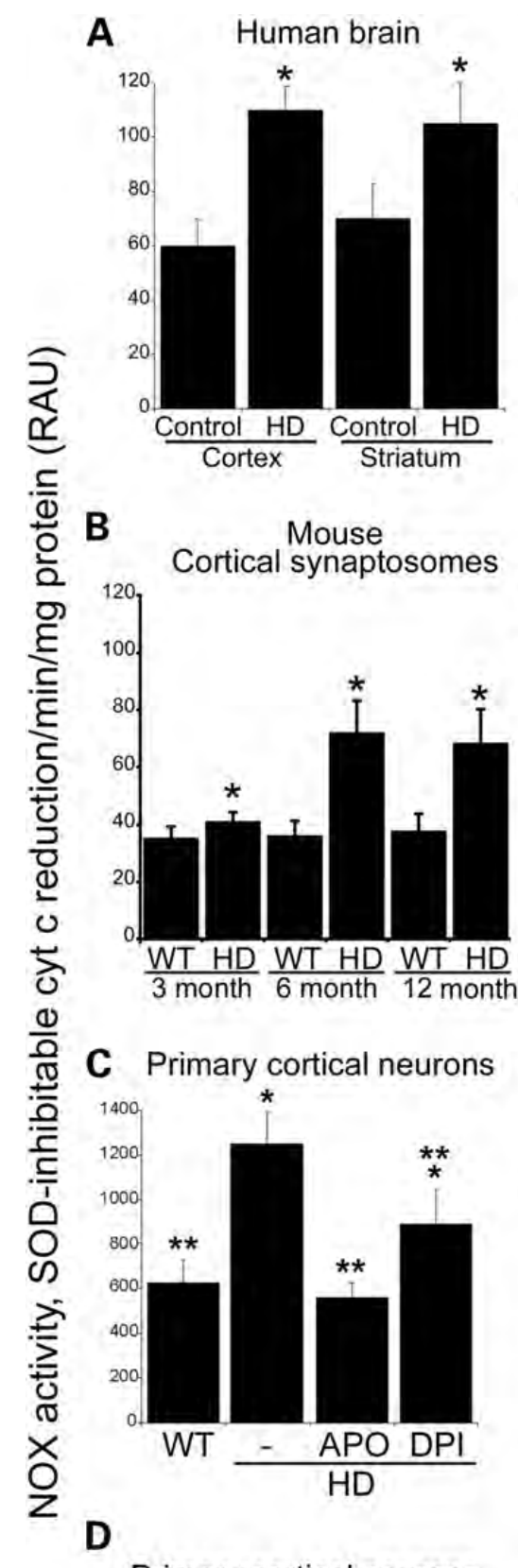

HD human brain (cortex)

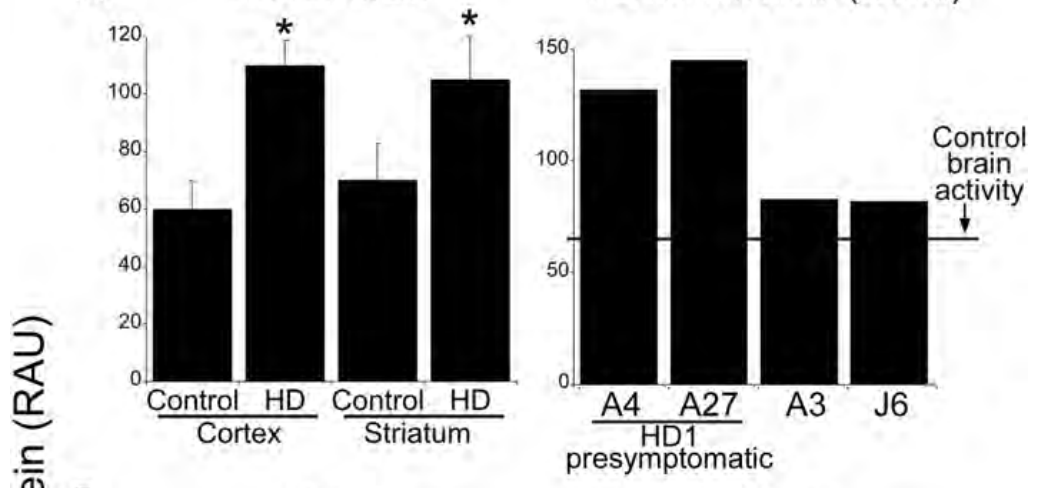

Primary cortical neurons

Primary striatal neurons
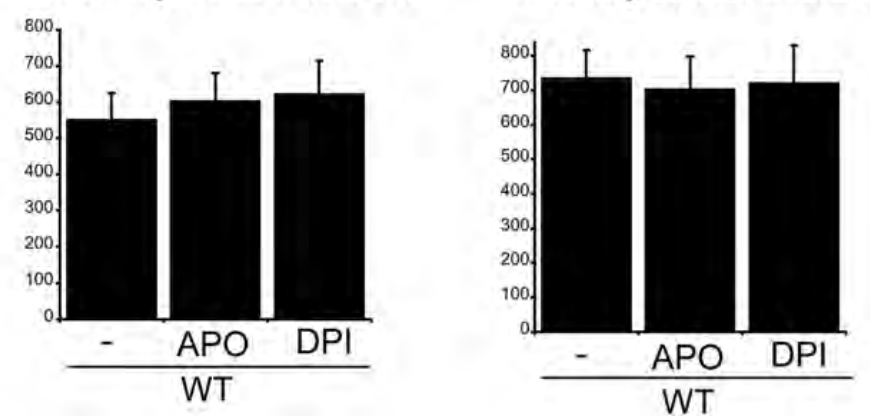

Figure 1. NOX activity is increased in human $\mathrm{HD}$ brain, in $\mathrm{HD}^{140 \mathrm{Q} / 140 \mathrm{Q}}$ mouse brain synaptosomes, and in $\mathrm{HD}{ }^{140 \mathrm{Q} / 140 \mathrm{Q}}$ primary neurons. NOX activity was measured as the reduction of cytochrome $\mathrm{c}$ in human brain samples (A), mouse brain synaptosomes $(\mathbf{B})$ and in primary cortical and striatal neurons $(\mathbf{C}$ and D) as described in Materials and Methods section. (A) Samples from human brain, cortex and striatum, were obtained according to Materials and Methods. NOX activity was increased in both cortex and striatum of HD brains relative to controls, graphed as mean + SD. Human cortex: Control $60.00+9.8$, HD $97.10 \pm 16.06, n=4$, Student's $t$-test, ${ }^{*} P<1.6 \mathrm{E}-05$. Human striatum: Control 71.12 \pm 12.90, HD $105.09 \pm 14.90, n=3$, Student's $t$-test, ${ }^{*} P<2.3 \mathrm{E}-04$. 
(Fig. 2A and B) and striatal neurons (Fig. 2E and F). The DCF signal in cell bodies and neurites of $\mathrm{HD}^{140 \mathrm{Q} / 140 \mathrm{Q}}$ cortical and striatal neurons was significantly greater than in WT neurons. Compared with corresponding WT neurons, $\mathrm{HD}^{140 \mathrm{Q} / 140 \mathrm{Q}}$ striatal neurons had a greater fold increase (Fig. 2G, 3-fold versus WT neurons) in the DCF signal than $\mathrm{HD}^{140 \mathrm{Q} / 140 \mathrm{Q}}$ cortical neurons (Fig. 2C, 1.5-2.0-fold versus WT neurons). Thus, ROS levels are higher in $\mathrm{HD}^{140 \mathrm{Q} / 140 \mathrm{Q}}$ primary striatal neurons than in WT neurons and higher in $\mathrm{HD}^{140 \mathrm{Q} / 140 \mathrm{Q}}$ striatal neurons than in $\mathrm{HD}^{140 \mathrm{Q} / 140 \mathrm{Q}}$ cortical neurons.

DCF-labeled $\mathrm{HD}^{140 \mathrm{Q} / 140 \mathrm{Q}}$ cortical and striatal neurons had significantly more varicosities on primary and secondary neurites than did DCF-labeled WT neurons (Fig. 2B, D, F and H). The spines of WT neurons were not visible because they had little or no DCF fluorescence (Fig. 3A and B). However, spines could be seen emerging from the neurites of $\mathrm{HD}^{140 \mathrm{Q} / 140 \mathrm{Q}}$ cortical neurons due to the high level of DCF fluorescence in the neurites (Fig. 3D and E). DCF fluorescence was also visible in axons of $\mathrm{WT}$ and $\mathrm{HD}^{140 \mathrm{Q} / 140 \mathrm{Q}}$ neurons (Fig. $3 \mathrm{~F}$ and G). The axon of a neuron was identified as the process that extended beyond the field of the other neurites. In comparison with WT neurons, the axons of $\mathrm{HD}^{140 \mathrm{Q} / 140 \mathrm{Q}}$ neurons had larger and more brightly fluorescent swellings (Fig. 3F and G). Co-labeling could not be combined with DCF fluorescence to confirm pre- and postsynaptic structures. However, based on morphology of DCF fluorescent structures, axonal boutons and spines of $\mathrm{HD}^{140 \mathrm{Q} / 140 \mathrm{Q}}$ had markedly increased ROS compared with WT neurons.

DCF is more sensitive to peroxides than superoxides (49) whereas dihydroethidine (DHE, aka hydroethidine) is more sensitive to superoxide. Since superoxide is the first product of NOX2 activity, we used DHE fluorescence as a measure of superoxide levels in primary neurons. DHE fluorescence was significantly elevated in the cytosol and nucleus of $\mathrm{HD}^{140 \mathrm{Q} / 140 \mathrm{Q}}$ primary neurons compared with WT neurons (Fig. $3 \mathrm{H}$ and I). These data support the idea that an excess of superoxide is a main source of oxidative stress and neurotoxicity in HD.

\section{Treatment with $\mathrm{H}_{2} \mathrm{O}_{2}$ increases ROS levels and varicosities in $W T$ and $\mathrm{HD}^{140 \mathrm{Q} / 140 \mathrm{Q}}$ cortical neurons}

We established that compared with WT cortical and striatal neurons, $\mathrm{HD}^{140 \mathrm{Q} / 140 \mathrm{Q}}$ cortical and striatal neurons had elevated ROS levels and altered morphology characterized by many neurite swellings. $\mathrm{H}_{2} \mathrm{O}_{2}$ is a secondary product of NOX2 activity. Exposing primary neurons to exogenous $\mathrm{H}_{2} \mathrm{O}_{2}$ increases oxidative stress in neurons $(52,53)$. To examine the relationship of ROS from $\mathrm{H}_{2} \mathrm{O}_{2}$ to changes in neuronal morphology, we treated primary neurons for 10 min with $100 \mu \mathrm{M} \mathrm{H}_{2} \mathrm{O}_{2}$ and after $1 \mathrm{~h}$ loaded neurons with DCFDA and evaluated cultures for ROS using DCF. Although no evidence of cell death was evident $1 \mathrm{~h}$ after $\mathrm{H}_{2} \mathrm{O}_{2}$ treatment, the WT and $\mathrm{HD}^{140 \mathrm{Q} / 140 \mathrm{Q}}$ neurons showed increased DCF levels (Fig. 4A). The proportional increase in DCF fluorescence in somata and neurites was greater in WT neurons (somata: $2.0 \times$ and neurites: $2.2 \times$ ) than in $\mathrm{HD}^{140 \mathrm{Q} / 140 \mathrm{Q}}$ neurons $(1.6 \times$ and $1.3 \times)$ (Fig. 4B). The difference in response is probably explained by the higher basal levels of ROS in $\mathrm{HD}^{140 \mathrm{Q} / 140 \mathrm{Q}}$ neurons than WT neurons and a saturation effect of the $\mathrm{H}_{2} \mathrm{O}_{2}$ treatment on ROS levels. Varicosities were increased in $\mathrm{H}_{2} \mathrm{O}_{2}$-treated WT cells on primary and secondary neurites and in $\mathrm{HD}^{140 \mathrm{Q} / 140 \mathrm{Q}}$ neurons in primary neurites (Fig. 4A). The secondary neurites of $\mathrm{HD}^{140 \mathrm{Q} / 140 \mathrm{Q}}$ neurons had numerous varicosities in both untreated and $\mathrm{H}_{2} \mathrm{O}_{2}$-treated conditions (Fig. 4A, insets). Thus, exposure to $\mathrm{H}_{2} \mathrm{O}_{2}$ produces an increase in ROS and formation of varicosities in WT and $\mathrm{HD}^{140 \mathrm{Q} /}$ ${ }^{140 Q}$ neurons.

\section{NOX inhibitors reduce ROS levels and varicosities and increase neuronal viability in $\mathrm{HD}^{140 \mathrm{Q} / 140 \mathrm{Q}}$ neurons}

Having established that NOX activity is increased in $\mathrm{HD}^{140 \mathrm{Q} / 140 \mathrm{Q}}$ cortical and striatal neurons and coincides with elevated ROS, we tested whether inhibiting NOX activity could reduce ROS levels and protect $\mathrm{HD}^{140 \mathrm{Q} / 140 \mathrm{Q}}$ neurons from cell death. ROS levels as measured by DCF fluorescence were significantly reduced in $\mathrm{HD}^{140 \mathrm{Q} / 140 \mathrm{Q}}$ cortical and striatal neurons to the level of WT neurons in the presence of APO or DPI (Fig. 5). Treatment with APO or DPI at 5 DIV reduced the ROS levels in the soma and neurites of $\mathrm{HD}^{140 \mathrm{Q} / 140 \mathrm{Q}}$ neurons. The frequency of neurons with varicosities on primary and secondary neurites was also significantly reduced in $\mathrm{HD}^{140 \mathrm{Q} / 140 \mathrm{Q}}$ neurons treated with APO or DPI or with VAS2870, which is more selective for NOX2 (Fig. 5). To assess the impact of APO and DPI on neuron survival, we performed an 3-(4,5-dimethyl-2-thiazolyl)-2,5-diphenyl$2 \mathrm{H}$-tetrazolium bromide (MTT) assay in cortical neurons at 10 DIV and in striatal neurons at 10 and 17 DIV. At 10 $\mathrm{DIV}, \sim 30 \%$ of $\mathrm{HD}^{140 \mathrm{Q} / 140 \mathrm{Q}}$ cortical neurons die compared

Two of the HD samples from human cortex correspond to presymptomatic patients (A4 and A27), and these samples showed higher activity levels for NOX than the other two HD samples (A3 and J6, right graph, presymptomatic HD cortex: $\mathrm{A} 4=118.00 ; \mathrm{A} 27=126.00$; other HD cortex samples: $\mathrm{A} 3=88.33$ and J6 $=$ 82.00). (B) Synaptosomes from brains of 3-, 6- and 12-month-old mice were obtained as described in Materials and Methods, graphed as mean \pm SD. NOX activity was significantly higher in $\mathrm{HD}^{140 \mathrm{Q} / 140 \mathrm{Q}}$ synaptosomes at all three ages compared with WT synaptosomes from the same group; however, the activity was highest in $\mathrm{HD}^{140 \mathrm{Q} / 140 \mathrm{Q}}$ synaptosomes of 6 and 12 months of age, ${ }^{*} P<0.05$. Left graph, cortical synaptosomes: 3 -month WT $35.07 \pm 4.27$, HD $40.73 \pm$ $3.55, n=5$, Student's $t$-test, $P<0.052$; 6-month WT $36.68 \pm 5.51$, HD $71.70 \pm 11.78, n=3$, Student's $t$-test, $P<0.008 ; 12$-month WT 33.47 \pm 6.30 , HD $68.27 \pm 11.96, n=3$, Student's $t$-test, $P<0.009$. Right graph, striatal synaptosomes: 3 -month WT $35.87 \pm 3.65, \mathrm{HD} 44.53 \pm 5.22, n=5$, Student's $t$-test, $P<0.012 ; 6$-month WT $40.48 \pm 3.85$, HD 102.23 $\pm 11.1, n=3$, Student's $t$-test, $P<0.0008$; 12 -month WT 41.20 \pm 4.40 , HD 74.40 $\pm 11.6, n=3$, Student's $t$-test, $P<0.0007$. (C) Cortical and striatal neurons were treated with APO $(50 \mu \mathrm{M})$ and DPI $(0.1 \mu \mathrm{M})$ at 5 DIV and harvested at 8 DIV. NOX activity was significantly elevated in both cortical and striatal $\mathrm{HD}^{140 \mathrm{Q} / 140 \mathrm{Q}}$ neurons compared with their WT counterparts. APO and DPI significantly reduced NOX in $\mathrm{HD}^{140 \mathrm{Q} / 140 \mathrm{Q}}$ neurons. Cortical neurons: WT $625.17+105.24$, HD $1245.40+143.45$, HD + APO 564.46 + 65.46, HD + DPI 889.17 + 159.76, 3 experiments in triplicate, Student's $t$-test, ${ }^{*} P<0.0002$ versus untreated WT neurons, ${ }^{* *} P<0.0005$ versus untreated $\mathrm{HD}^{140 \mathrm{Q} / 140 \mathrm{Q}}$ neurons; striatal neurons: WT $727.00 \pm$ 105.45, HD 1258.40 \pm 130.05 , HD + APO 883.65 \pm 68.68 , HD + DPI $865.80 \pm 49.60,3$ experiments in triplicate, Student's $t$-test, ${ }^{*} P<0.0001$ versus untreated WT neurons, ${ }^{* *} P<0.0002$ versus untreated $\mathrm{HD}^{140 \mathrm{Q} / 140 \mathrm{Q}}$ neurons. (D) WT cortical and striatal neurons treated with APO and DPI are not different from untreated neurons. 
Primary cortical neurons
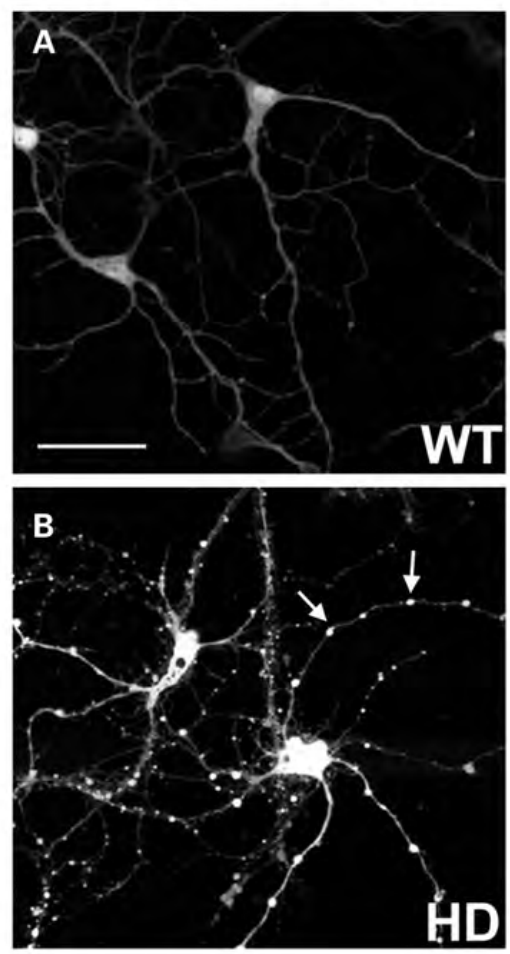

C

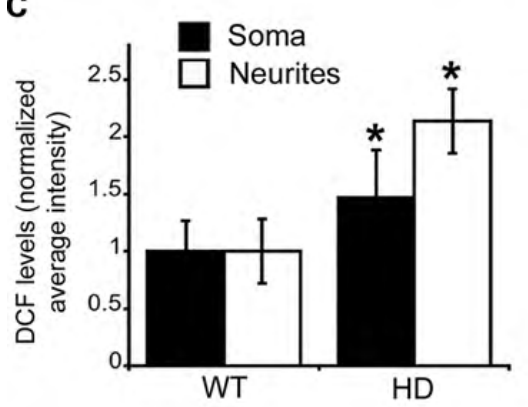

Primary neurites

Secondary neurites

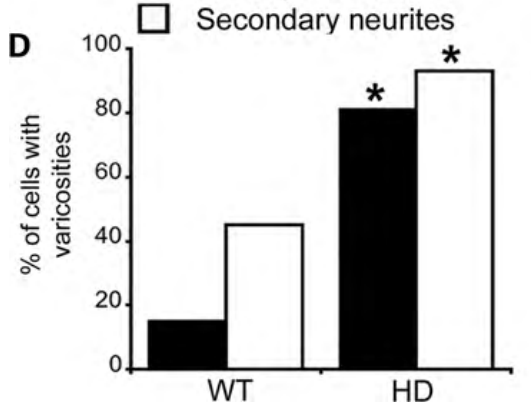

Primary striatal neurons
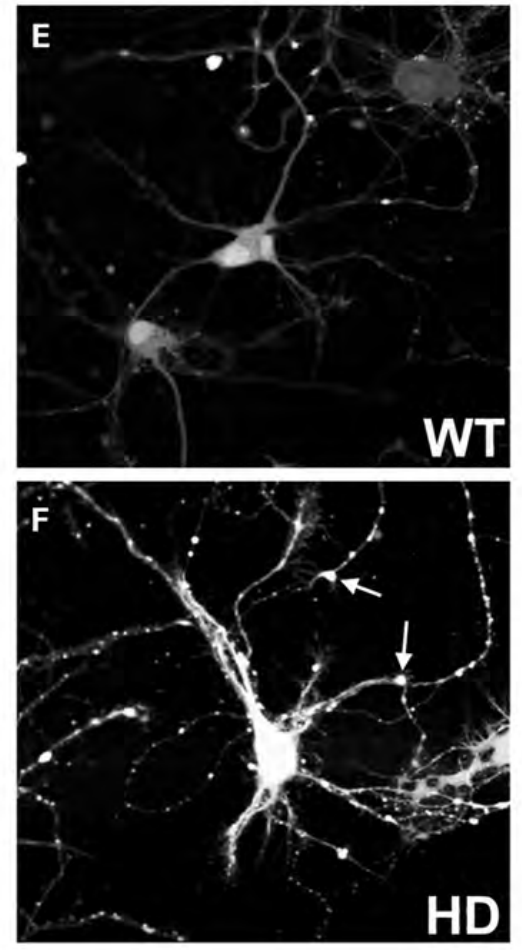

G
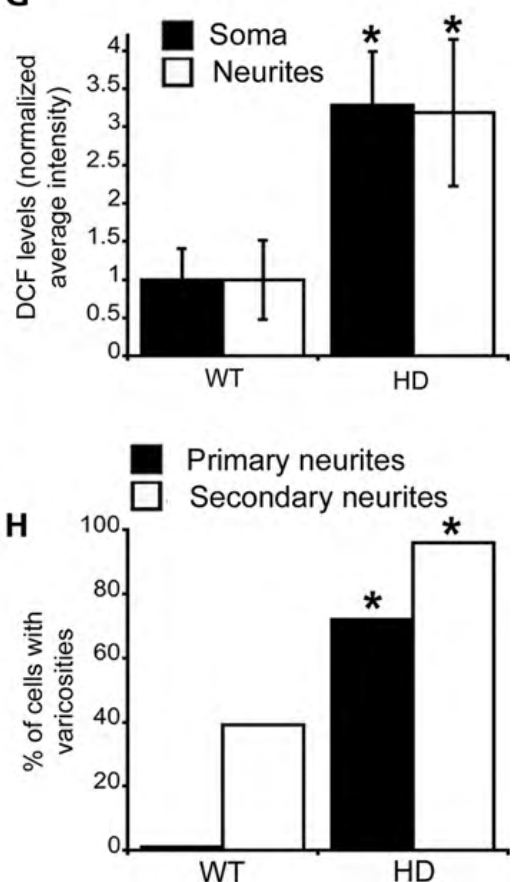

Figure 2. ROS levels detected by DCF fluorescence are significantly elevated in the somata and neurites of $\mathrm{HD}^{140 \mathrm{Q} / 140 \mathrm{Q}}$ primary cortical and striatal neurons. Shown are confocal microscope images of living DCF fluorescent cortical (A and $\mathbf{B})$ and striatal $(\mathbf{E}$ and $\mathbf{F}) \mathrm{WT}$ and $\mathrm{HD}^{140 \mathrm{Q} / 140 \mathrm{Q}}$ primary neurons at 8 DIV. Arrows in B and F identify varicosities. DCF fluorescence reflects levels of ROS which are increased in HD ${ }^{140 Q / 140 Q}$ neurons compared with WT neurons. Scale bar in (A) represents $25 \mu \mathrm{m}$. (C and $\mathbf{G}$ ) ROS levels were quantified as the average DCF fluorescence intensity in soma (filled bars) and neurites (open bars) of $\mathrm{WT}$ and $\mathrm{HD}^{140 \mathrm{Q} / 140 \mathrm{Q}}$ neurons using Image $\mathrm{J}$ software as explained in Materials and Methods. Results are expressed as normalized WT-DCF average intensity in soma and neurites of WT and $\mathrm{HD}^{140 \mathrm{Q} / 140 \mathrm{Q}}$ neurons as mean $\pm \mathrm{SD}$. (C) Cortical neurons: soma: WT $1 \pm 0.26$ and $\mathrm{HD} 1.49 \pm 0.31,3$ independent experiments $\left(n=68 \mathrm{WT}\right.$ neurons and $66 \mathrm{HD}^{140 \mathrm{Q} / 140 \mathrm{Q}}$ neurons), Student's $t$-test, ${ }^{*} P<0.0001$, neurites: WT $1 \pm 0.42$ and $\mathrm{HD} 2.24 \pm 0.34$, three independent experiments $\left(n=68 \mathrm{WT}\right.$ neurites and $66 \mathrm{HD}^{140 \mathrm{Q} / 140 \mathrm{Q}}$ neurites), Student's $t$-test, ${ }^{*} P<0.0001$. (G) Striatal neurons: soma: WT $1+0.43$ and $\mathrm{HD}$ $3.41 \pm 0.64\left(n=50 \mathrm{WT}\right.$ neurons and $52 \mathrm{HD}^{140 \mathrm{Q} / 140 \mathrm{Q}}$ neurons from three independent experiments), Student's $t$-test, ${ }^{*} P<0.00001$, neurites: WT $1 \pm 0.52$ and $\mathrm{HD}^{140 \mathrm{Q} / 140 \mathrm{Q}} 3.26 \pm 0.83,\left(n=35 \mathrm{WT}\right.$ neurites and $35 \mathrm{HD}^{140 \mathrm{Q} / 140 \mathrm{Q}}$ neurites from three independent experiments), Student's $t$-test, ${ }^{*} P<0.00001$. (D and $\mathbf{H})$ Bar graphs show percent of $\mathrm{WT}$ and $\mathrm{HD}^{140 \mathrm{Q} / 140 \mathrm{Q}}$ neurons with varicosities in primary and secondary neurites. (D) Cortical neurons: $n=20 \mathrm{WT}$ neurons, and $16 \mathrm{HD}^{140 \mathrm{Q} / 140 \mathrm{Q}}$ neurons, $\chi^{2}$ test, ${ }^{*} P<0.002$. (H) Striatal neurons: $n=35$ WT neurons, and $35 \mathrm{HD}^{140 \mathrm{Q} / 140 \mathrm{Q}}$ neurons, $\chi^{2}$ test, ${ }^{*} P<0.0001$. 


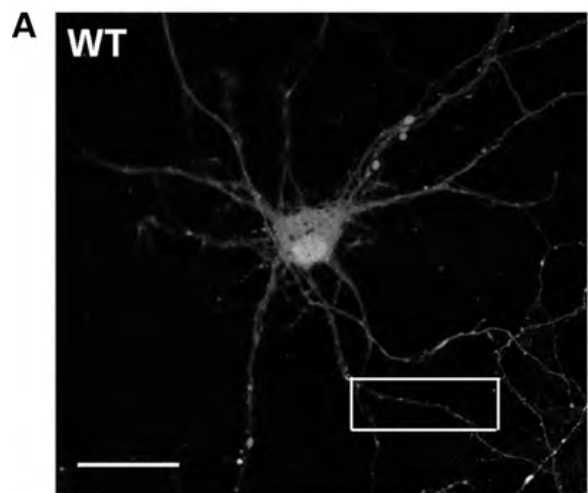

B

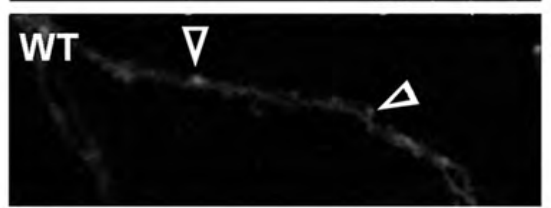

$\mathbf{F}$

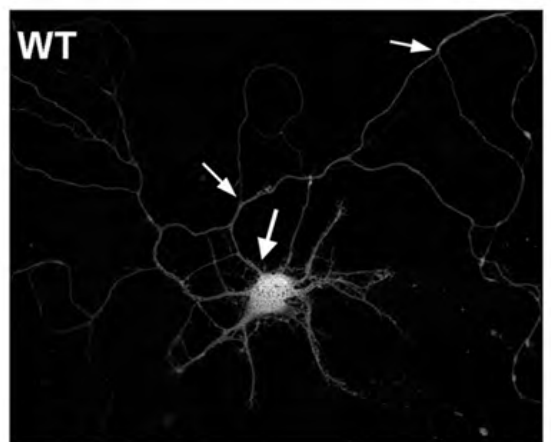

H WT
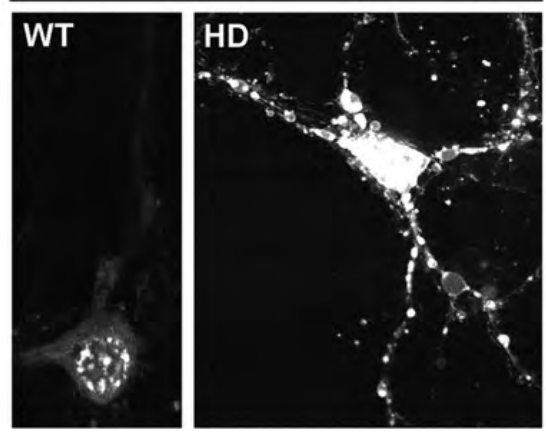
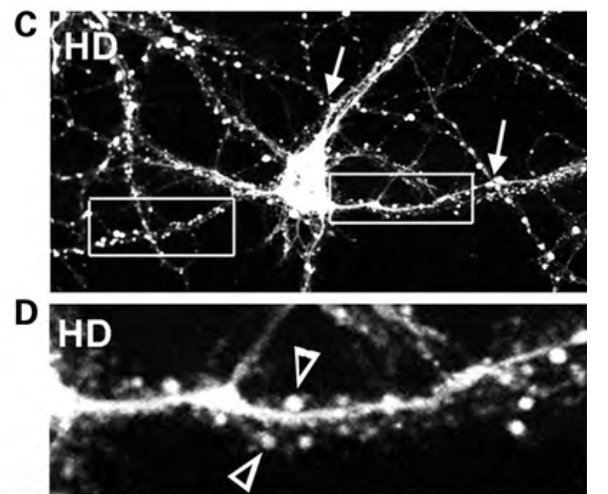

E

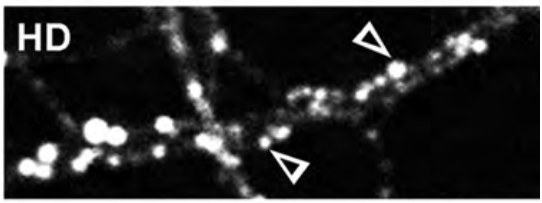

$\mathbf{G}$

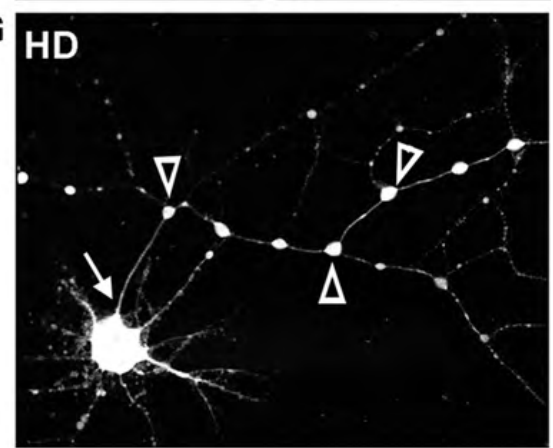

I

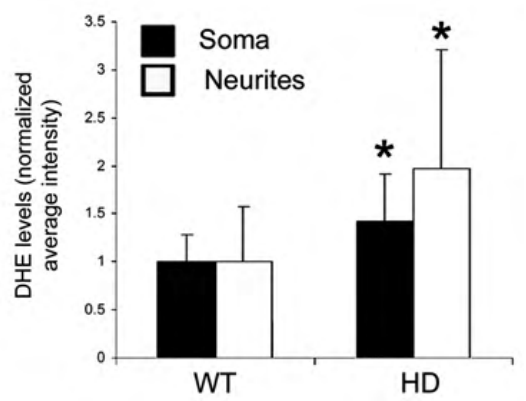

Figure 3. Spines and axons of $\mathrm{HD} 140 \mathrm{Q} / 140 \mathrm{Q}$ primary cortical neurons have high levels of ROS as detected by DCF fluorescence. Shown are images of living neurons from WT $(\mathbf{A}, \mathbf{B}, \mathbf{F})$ and $\mathrm{HD}^{140 \mathrm{Q} / 140 \mathrm{Q}}(\mathbf{C}-\mathbf{E}, \mathbf{G})$ cultures of embryonic cortex grown to 8 DIV. (A and C) Positive DCF-labeled WT $(\mathrm{A})$ and $\mathrm{HD}{ }^{140 \mathrm{Q} / 140 \mathrm{Q}}(\mathrm{C})$ neurons. The boxed areas are shown at higher magnification in $\mathrm{B}$ for the WT neuron and in $\mathrm{D}$ and $\mathrm{E}$ for the $\mathrm{HD}^{140 \mathrm{Q} / 140 \mathrm{Q}}$ neuron. Varicosities are prominent in $\mathrm{HD} \mathrm{D}^{140 \mathrm{Q} / 140 \mathrm{Q}}$ neurites (C and G, arrows in C and open arrowheads in G) and not WT neurites (A and F). Scale bar in (A) represents $25 \mu \mathrm{m}$. (D and E) Small brightly DCF fluorescent spines (open arrowheads) occur along the neurites of the $\mathrm{HD}^{140 \mathrm{Q} / 140 \mathrm{Q}}$ neuron shown in $(\mathrm{C})$. ( $\mathrm{F}$ and $\left.\mathrm{G}\right)$ The axon is recognized as the only neurite that emerges from the cell body (arrow) and form branches that extend beyond the field of the other neurites. Note the large DCF fluorescent varicosities (open arrowheads) in the axon of the $\mathrm{HD}^{140 \mathrm{Q} / 140 \mathrm{Q}}$ neuron. $(\mathbf{H})$ Cortical neurons with DHE fluorescence. Live cell images of WT and $\mathrm{HD}^{140 \mathrm{Q} / 140 \mathrm{Q}}$ primary cortical neurons at 8 DIV show fluorescence from DHE which preferentially reacts with superoxide. Note that the DHE is retained in abnormal swellings of $\mathrm{HD}{ }^{140 \mathrm{Q} / 140 \mathrm{Q}}$ neurons. (I) Bar graph shows densitometry results for DHE fluorescent neurons. Student's $t$-test ${ }^{*} P<0.01, n=19 \mathrm{WT}$ and $24 \mathrm{HD}^{140 \mathrm{Q} / 140 \mathrm{Q}}$ neurons.

with WT neurons, as reported previously (15). In striatal neurons survival measured by MTT transformation was reduced by $\sim 22 \%$ at 10 DIV and by $\sim 35 \%$ at $17 \mathrm{DIV}$ (Fig. 6A). Treatment with APO or DPI at 5 DIV significantly increased viability of $\mathrm{HD}^{140 \mathrm{Q} / 140 \mathrm{Q}}$ cortical neurons at $10 \mathrm{DIV}$ and striatal $\mathrm{HD}^{140 \mathrm{Q} / 140 \mathrm{Q}}$ neurons at 10 and $17 \mathrm{DIV}$ as measured by the MTT assay (Fig. 6A). In the presence of APO or DPI, the survival of $\mathrm{HD}^{\mathrm{P} 40 \mathrm{Q} / 140 \mathrm{Q}}$ cortical neurons at 10 DIV was improved by $\sim 80$ and $50 \%$, respectively, when compared with untreated $\mathrm{HD}^{140 \mathrm{Q} / 140 \mathrm{Q}}$ cortical neurons; the survival of $\mathrm{HD}^{140 \mathrm{Q} / 140 \mathrm{Q}}$ striatal neurons at $17 \mathrm{DIV}$ was improved by 97 and 50\%, respectively. These findings suggested that APO was more effective than DPI. The NOX inhibitors had no effect on the survival or levels of DCF fluorescence in WT neurons (Fig. 6B). Altogether, these data showed that inhibition of NOX activity attenuated ROS levels in $\mathrm{HD}^{140 \mathrm{Q} / 140 \mathrm{Q}}$ neurons and improved neuronal morphology and cell survival. NOX2 is the major source of NOX 
A
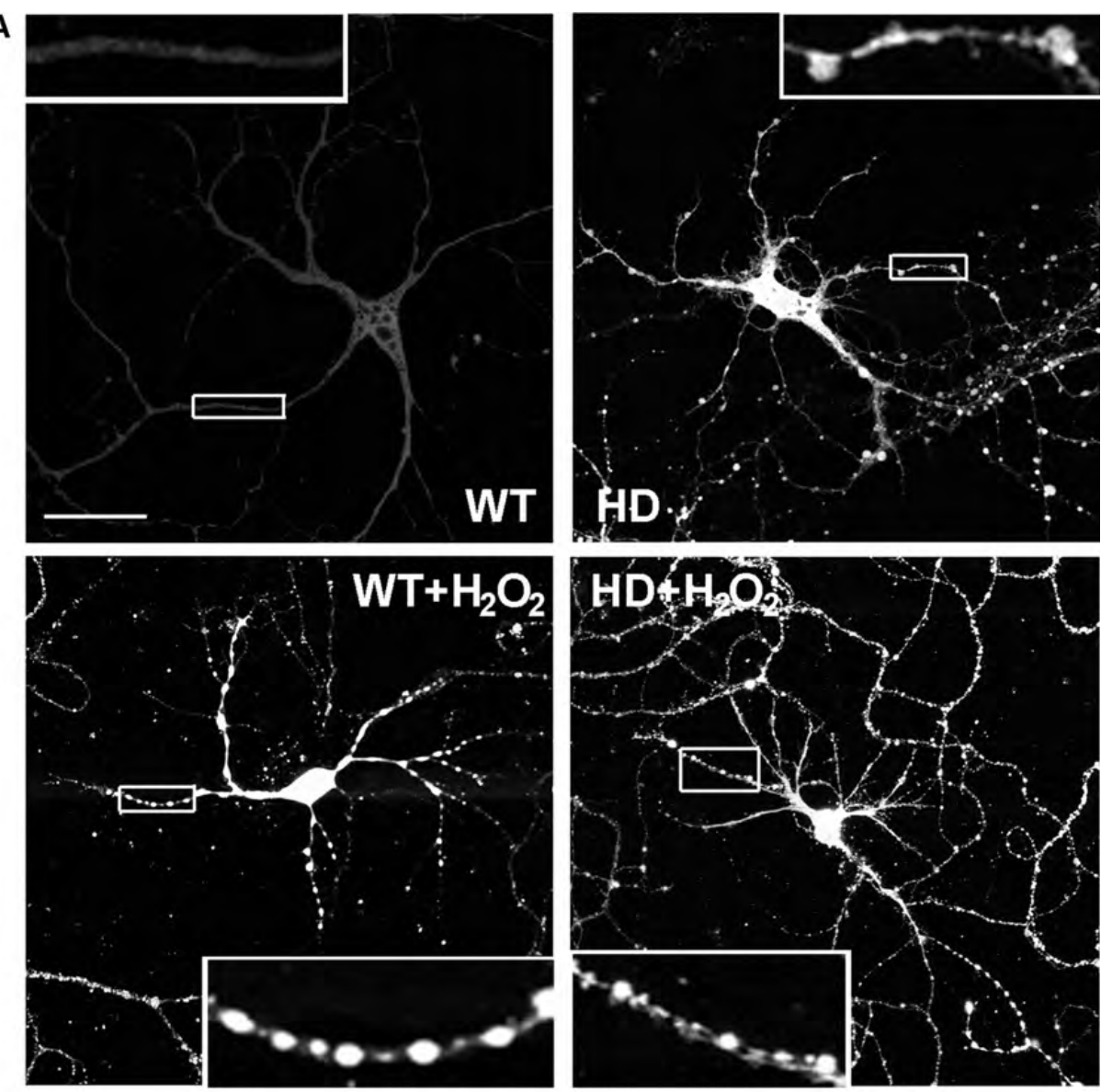

B

Soma

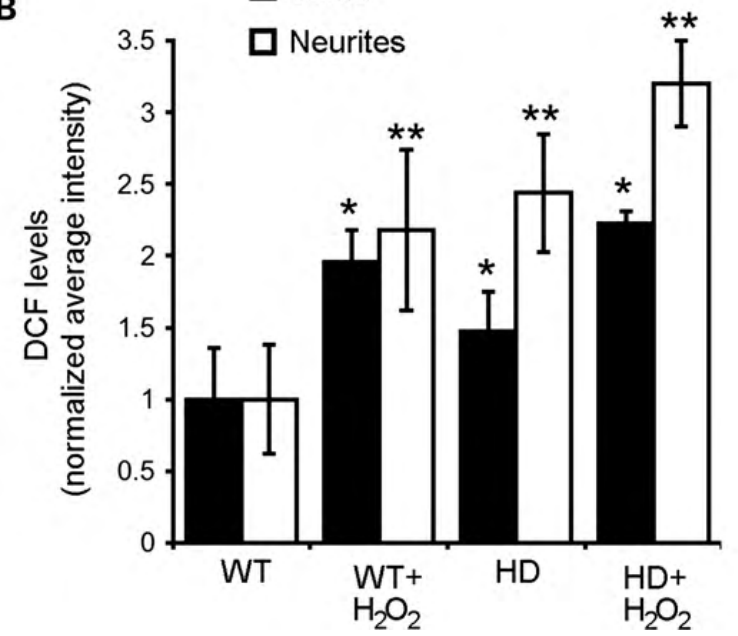

Figure 4. ROS levels and neurite varicosities increase in WT and $\mathrm{HD}^{140 \mathrm{Q} / 140 \mathrm{Q}}$ cortical neurons treated with $\mathrm{H}_{2} \mathrm{O}_{2}$. (A) Shown are confocal images of DCF-labeled WT and $\mathrm{HD}^{140 \mathrm{Q} / 140 \mathrm{Q}}$ cortical neurons that were untreated or treated with $100 \mu \mathrm{M} \mathrm{H}_{2} \mathrm{O}_{2}$ as explained in the Materials and Methods. Insets are higher magnification images of the boxed areas of the neurite. Varicosities are prominent in $\mathrm{H}_{2} \mathrm{O}_{2}$-treated neurons compared with untreated neurons. Scale bar in (A) represents $25 \mu \mathrm{m}$. (B) Quantitative analysis of average intensity of DCF fluorescence in soma and neurites of $\mathrm{H}_{2} \mathrm{O}_{2}$-treated neurons relative to untreated WT neurons. Mean \pm SD, soma: WT $1.00 \pm 0.36$; WT $+\mathrm{H}_{2} \mathrm{O}_{2} 1.96 \pm 0.22$; HD $1.47 \pm 0.28 ; \mathrm{HD}+\mathrm{H}_{2} \mathrm{O}_{2} 2.30 \pm 0.08$. Neurites: WT 1.00 \pm 0.38 ; $\mathrm{WT}+\mathrm{H}_{2} \mathrm{O}_{2} 2.18 \pm 0.56 ; \mathrm{HD} 2.44 \pm 0.41 ; \mathrm{HD}+\mathrm{H}_{2} \mathrm{O}_{2} 3.20 \pm 0.30, n=22$ neurons analyzed per group in three independent experiments, Student's $t$-test, ${ }^{*} P<0.001$ versus untreated WT neurons, ${ }^{* *} P<0.005$ versus untreated $\mathrm{HD}^{140 \mathrm{Q} / 140 \mathrm{Q}}$ neurons.

activity in neurons. Since APO and DPI may have nonspecific effects and inhibit the activity of multiple NOX enzymes, we also evaluated the effects of a small molecule VAS2870 which is reported to selectively inhibit NOX2 (54). Similar to APO and DPI, VAS2870 increased the survival of $\mathrm{HD}^{140 \mathrm{Q} / 140 \mathrm{Q}}$ cortical neurons, suggesting that excess NOX2 activity 


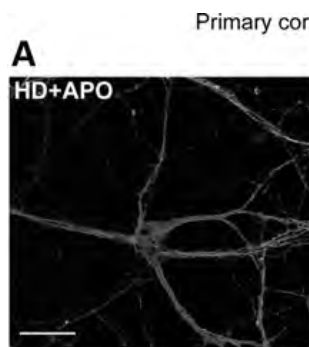

cal neurons

B
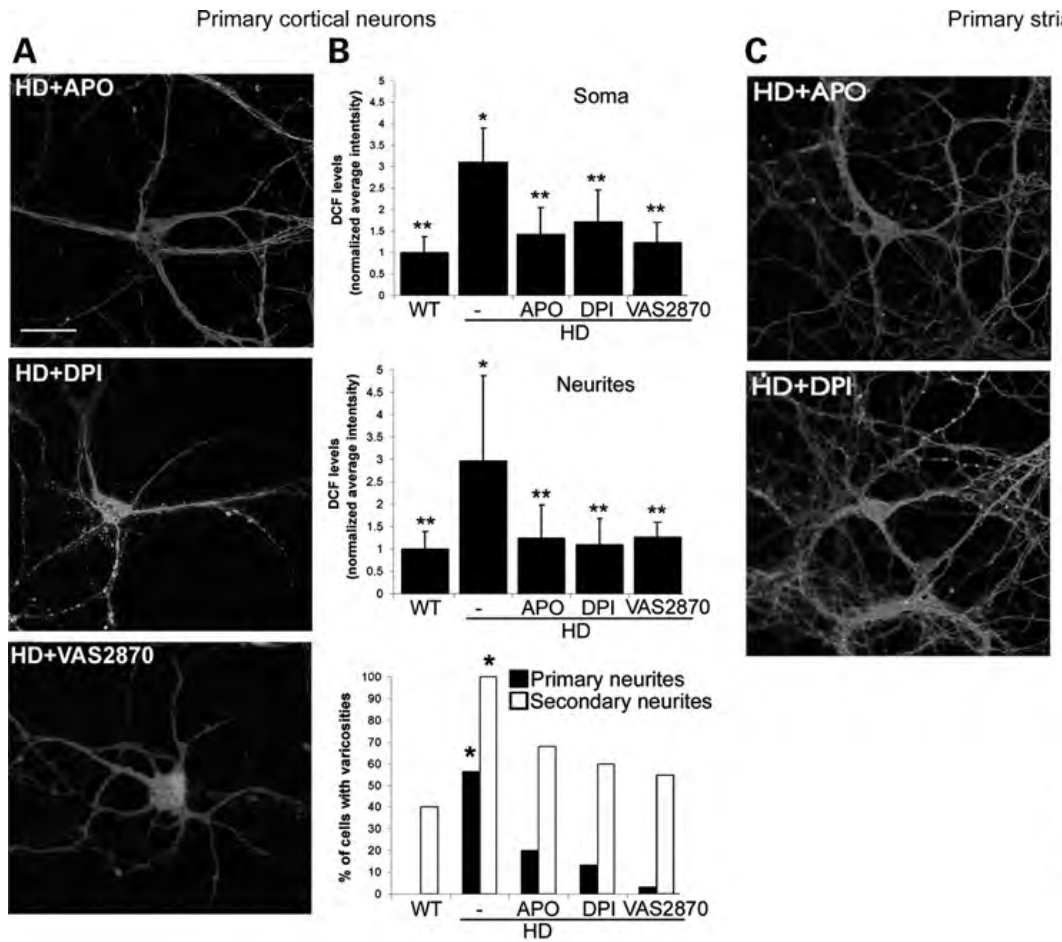

tal neurons

D
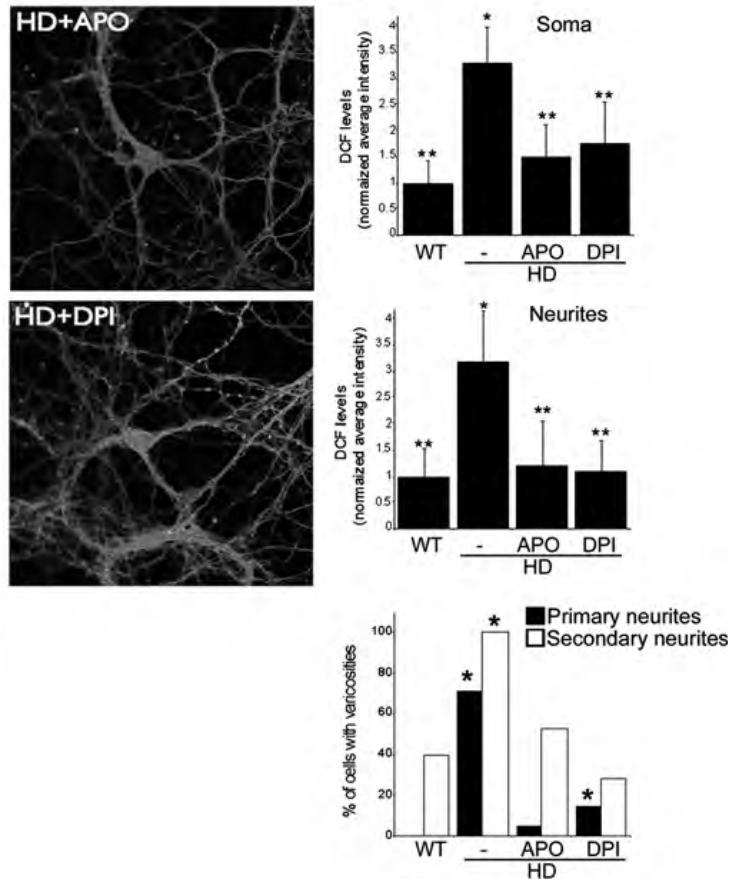

Figure 5. NOX inhibitors reduce ROS levels and neurite varicosities in $\mathrm{HD} \mathrm{140Q}^{140 \mathrm{Q}}$ neurons. (A and C) Confocal images of DCF-labeled cortical (A) and striatal

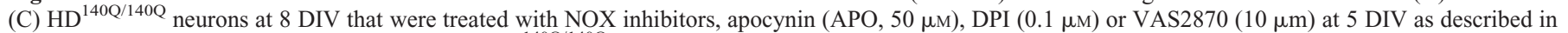

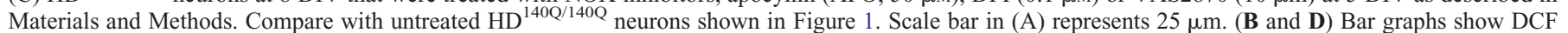

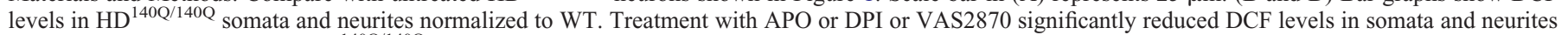
of cortical (B) and striatal (D) $\mathrm{HD}^{140 \mathrm{Q} / 140 \mathrm{Q}}$ neurons. Values indicate mean $\pm \mathrm{SD}$. Cortical neurons, soma: WT $1.00 \pm 0.36, \mathrm{HD} 3.1 \pm 0.80, \mathrm{HD}+\mathrm{APO} 1.43 \pm$ $0.62, \mathrm{HD}+\mathrm{DPI} 1.72 \pm 0.74, \mathrm{HD}+\mathrm{VAS} 28701.23 \pm 0.47$; neurites: WT $1.00 \pm 0.39, \mathrm{HD} 2.96 \pm 1.92, \mathrm{HD}+\mathrm{APO} 1.25 \pm 0.74, \mathrm{HD}+\mathrm{DPI} 1.10 \pm 0.59, \mathrm{HD}+$ VAS2870 $1.27 \pm 0.34 ; n=5-33$ neurons from three independent experiments. Student's $t$-test, ${ }^{*} P<0.05$ versus WT neurons, $* * P<0.05$ versus untreated $\mathrm{HD}^{140 \mathrm{Q} / 140 \mathrm{Q}}$ neurons. Striatal neurons, soma: WT $1.00 \pm 0.41$, HD $3.28 \pm 0.70, \mathrm{HD}+\mathrm{APO} 1.48 \pm 0.64$, HD + DPI $1.76 \pm 0.83$; neurites: WT $1.00 \pm 0.52$, HD $3.19 \pm 0.96, \mathrm{HD}+\mathrm{APO} 1.20 \pm 0.84$, HD + DPI $1.08 \pm 0.62, n=6-23$ neurons from three independent experiments. Student's $t$-test, $* P<0.005$ versus WT neurons, ${ }^{* *} P<0.005$ versus untreated $\mathrm{HD}^{140 \mathrm{Q} / 140 \mathrm{Q}}$ neurons. Varicosities were measured as described in Materials and Methods. Lower bar graphs in (B) and (D) show the percentage of cortical and striatal neurons with DCF-labeled varicosities on primary or secondary neurites in untreated or NOX inhibitor-treated cultures. No varicosities were observed on primary neurites in WT neurons. Treatments with APO, DPI and VAS2870 (only cortical

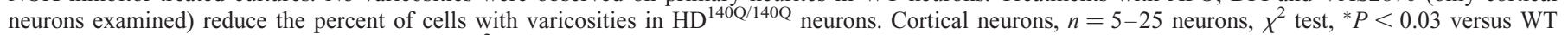
neurons, and striatal neurons, $n=35$ neurons, $\chi^{2}$ test, ${ }^{*} P<0.0001$ versus WT neurons.

contributed to cell death in HD (Fig. 6C). Superoxide anion is the main source of ROS generated by NOX2; therefore, we examined the effects of the superoxide quencher EUK189 on HD neuron survival by the MTT assay. $\mathrm{HD}^{140 \mathrm{Q} / 140 \mathrm{Q}}$ neurons treated with $5 \mu \mathrm{M}$ EUK189 at 5 DIV exhibited a significant increase in viability at 10 DIV compared with untreated $\mathrm{HD}^{140 \mathrm{Q} /}$ ${ }^{140 Q}$ neurons (Fig. 6C). Altogether, the findings suggest that superoxide anion contributes to increased ROS levels in $\mathrm{HD}^{140 \mathrm{Q} / 140 \mathrm{Q}}$ neurons as a result of an elevated NOX2 activity.

\section{A catalytic subunit of NOX2 and mutant Htt colocalize at plasma membrane lipid rafts in primary $\mathrm{HD}^{140 \mathrm{Q} / 140 \mathrm{Q}}$ neurons}

Gp91-phox is a component of the catalytic core of NOX2, is required for NOX2 activity and has been identified in mouse brain and hippocampal neurons using biochemical and immunohistochemical methods $(29,55,56)$. By western blot assay with anti-gp91-phox antibody, we detected a prominent band at $\sim 67 \mathrm{kDa}$ and a weaker band at $\sim 65 \mathrm{kDa}$ in WT mouse brain lysates. These bands $(67 / 65 \mathrm{kDa})$ did not appear in brain lysates of a mouse null for gp91-phox $\left(\mathrm{NOX}^{-}{ }^{-}\right.$, strain B6.129s-Cybb $b^{\text {tm1Din }} / \mathrm{J}$, from The Jackson Laboratory) (Fig. 7A). Gp91-phox immunoreactive bands migrating at $67 / 65 \mathrm{kDa}$ were also detected in synaptosomes prepared from the cortex and striatum of 3-month-old WT and $\mathrm{HD}^{140 \mathrm{Q} / 140 \mathrm{Q}}$ mice (Fig. 7B). Thus a protein essential for NOX2 activity is detected in brain regions affected in HD.

Gp91-phox and p22-phox are membrane subunits of NOX2 that reside in lipid rafts $(57-59)$. Sodium dodecyl sulfatepolyacrylamide gel electrophoresis (SDS-PAGE) and western blot analysis of detergent-resistant membranes (DRMs) prepared from primary WT and $\mathrm{HD}^{140 \mathrm{Q} / 140 \mathrm{Q}}$ neuronal cultures showed gp91-phox codistributed with the lipid raft marker G $\alpha \mathrm{q}$ (Fig. 7C). No significant difference between WT and $\mathrm{HD}^{140 \mathrm{Q} / 140 \mathrm{Q}}$ neurons was detected in the levels of gp91-phox in lipid raft fractions relative to total DRM fractions $(\mathrm{WT}=46.6 \pm 7.1 \%$ and $\mathrm{HD}=50.8 \pm 23.1 \%, P=0.7$, $n=5$ DRM fractionations per group). We previously showed that Htt is also detected in lipid raft fractions of WT and $\mathrm{HD}^{140 \mathrm{Q} / 140 \mathrm{Q}}$ primary cortical neurons $(15)$. To determine whether gp91-phox and Htt colocalized in plasma membrane 

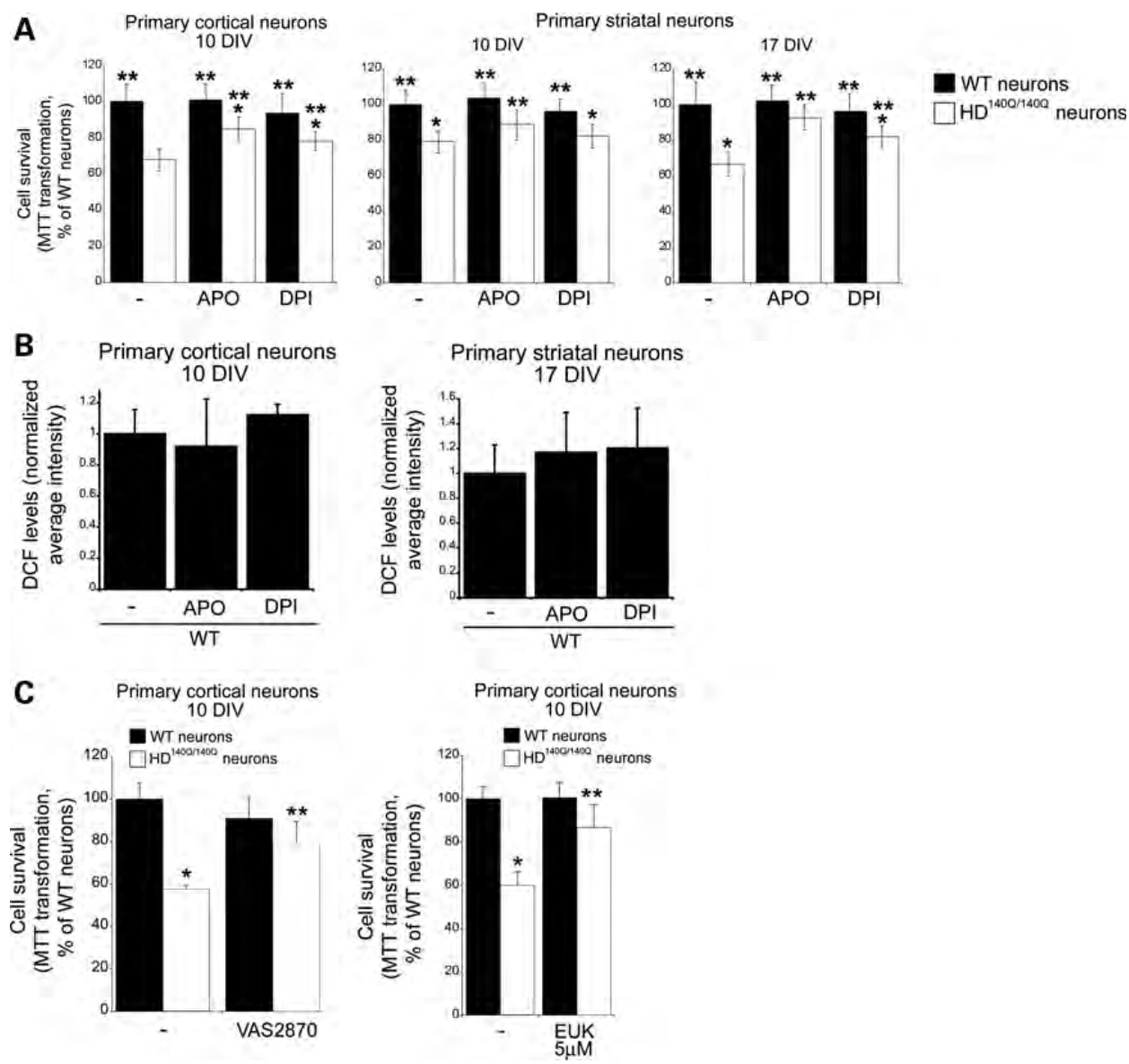

Figure 6. NOX inhibitors ameliorate neuronal death of $\mathrm{HD}^{140 \mathrm{Q} / 140 \mathrm{Q}}$ cortical and striatal neurons. (A) Survival of WT and $\mathrm{HD}^{140 \mathrm{Q} / 140 \mathrm{Q}}$ neurons was determined using the MTT assay at 10 DIV for cortical neurons and at 10 DIV and 17 DIV for striatal neurons after no treatment or treatment with apocynin (APO, $50 \mu \mathrm{M}$ ) and DPI $(0.1 \mu \mathrm{M})$. Data expressed as the percent of cell survival normalized to untreated WT neurons $(100 \%)$. Cortical neurons: WT $100.00 \pm 9.98$, HD $67.90 \pm$ 6.20 , WT + APO $101.30 \pm 8.30, \mathrm{HD}+\mathrm{APO} 84.90 \pm 6.30$, WT + DPI 93.80 $\pm 10.90, \mathrm{HD}+\mathrm{DPI} 78.60 \pm 5.10, n=12$ samples from three independent experiments, Student's $t$-test, ${ }^{*} P<0.001$ versus WT neurons; ${ }^{* *} P<0.001$ versus untreated $\mathrm{HD}{ }^{140 \mathrm{Q} / 140 \mathrm{Q}}$ neurons. Striatal neurons $10 \mathrm{DIV}:$ WT $100.00 \pm 8.05$, $\mathrm{HD}$ $78.90 \pm 6.05$, WT + APO 103.56 $\pm 8.46, \mathrm{HD}+\mathrm{APO} 88.68 \pm 8.36$, WT + DPI $95.90 \pm 7.20, \mathrm{HD}+\mathrm{DPI} 82.23 \pm 6.45, n=12$ samples from three independent experiments, Student's $t$-test, ${ }^{*} P<0.001$ versus WT neurons; ${ }^{* *} P<0.001$ versus untreated $\mathrm{HD}^{140 \mathrm{Q} / 140 \mathrm{Q}}$ neurons. Striatal neurons $17 \mathrm{DIV}$ : WT $100.00 \pm 12.05$, HD $67.00+6.78$, WT + APO $102.40+8.79$, HD + APO $92.90+6.98$, WT + DPI $96.90+9.45$, HD + DPI $82.65+5.93, n=12$ samples from three independent experiments, Student's $t$-test, ${ }^{*} P<0.001$ versus WT neurons; ${ }^{* *} P<0.001$ versus untreated $\mathrm{HD}^{140 \mathrm{Q} / 140 \mathrm{Q}}$ neurons. (B) WT cortical and striatal neurons were treated with APO $(50 \mu \mathrm{M})$ and DPI $(0.1 \mu \mathrm{M})$ as described in Materials and Methods. DCF levels were not significantly different between WT neurons treated without or with APO or DPI. $N=32$ neurons per group. (C) Primary cortical neurons were treated at 5 DIV with the selective NOX2 inhibitor VAS2870 $(10 \mu \mathrm{M})$ or with the superoxide quencher EUK189 $(5 \mu \mathrm{M})$ and harvested for MTT assay at 10 DIV. The level of MTT transformation is expressed relative to untreated WT neurons. VAS2870 and EUK189 have little effect on WT neurons but significantly improve survival of HD ${ }^{140 Q / 140 Q}$ cortical neurons (VAS2870, ${ }^{*} P<0.0001$ versus untreated WT neurons, ${ }^{*} P<0.0005$ versus untreated $\mathrm{HD}^{140 \mathrm{Q} / 140 \mathrm{Q}}$ neurons; EUK189, ${ }^{*} P<0.037$ versus untreated WT neurons, ${ }^{* *} P<0.0023$ versus untreated $\mathrm{HD}^{140 \mathrm{Q} / 140 \mathrm{Q}}$ neurons). These results suggest that superoxide production contributes to excess ROS.

lipid rafts, we exposed living $\mathrm{WT}$ and $\mathrm{HD}^{140 \mathrm{Q} / 140 \mathrm{Q}}$ neurons to fluorescently tagged cholera toxin subunit-B (CTB), which binds to ganglioside M1 at lipid rafts (15). The CTB-labeled neurons were subsequently fixed for $30 \mathrm{~min}$ and labeled by immunohistochemistry using anti-gp91-phox or anti-Htt antibody or both antisera in the same cultures. Htt associates with intracellular and plasma membranes. Htt-labeling preferentially at the plasma membrane was optimized by omitting a detergent treatment prior to the antibody incubation step and using a 30-min fixation at $4^{\circ} \mathrm{C}$ which mildly permeabilized the plasma membrane. Results showed CTB fluorescent puncta in combination with either gp91-phox or with $\mathrm{Htt}$ immunoreactive fluorescent puncta distributed along the plasma membrane (Fig. 7D and E). In cultures where primary antisera or secondary antisera were omitted, there was no labeling for gp91-phox or Htt (Supplementary Material, Fig. S1). Since lipid rafts are submicroscopic in size, each fluorescent puncta identified by CTB at the plasma membrane in the light microscope is likely to represent a coalescence of multiple lipid rafts in the membrane. A quantitative analysis showed that the majority of CTB-labeled puncta co-localized with $\mathrm{Htt}$ in WT neurons $(92.5+9.3 \%)$ and with mutant $\mathrm{Htt}$ in $\mathrm{HD}^{140 \mathrm{Q} / 140 \mathrm{Q}}$ neurons $(96.4 \pm 12.6 \%)$. The mean proportion of CTB-positive puncta (lipid rafts) that colocalized gp91-phox or a combination of gp91-phox and Htt was significantly higher in $\mathrm{HD}^{140 \mathrm{Q} / 140 \mathrm{Q}}$ neurons than in WT neurons (Fig. 7F). These data suggest that the presence of mutant $\mathrm{Htt}$ in plasma membrane lipid rafts increases the lipid raft distribution of gp91-phox, an essential catalytic component of NOX2. 
A

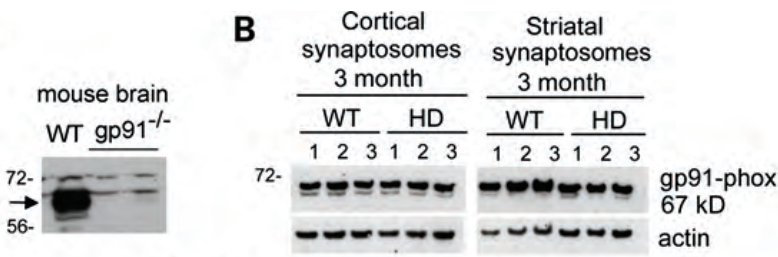

C

WT DRM

HD DRM
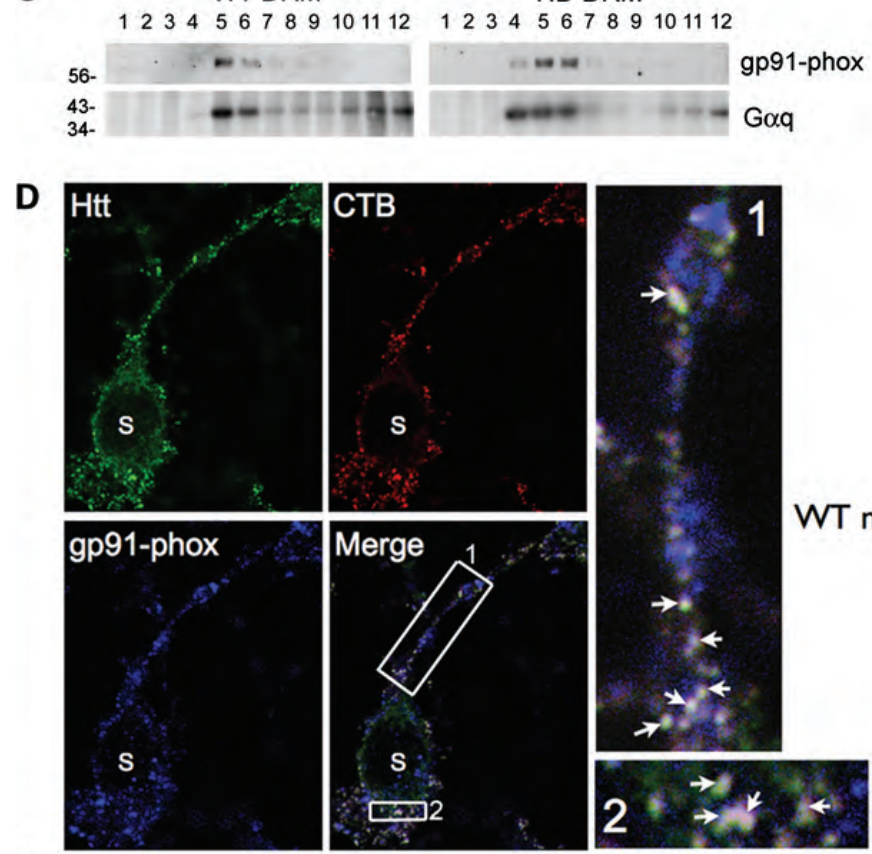

E
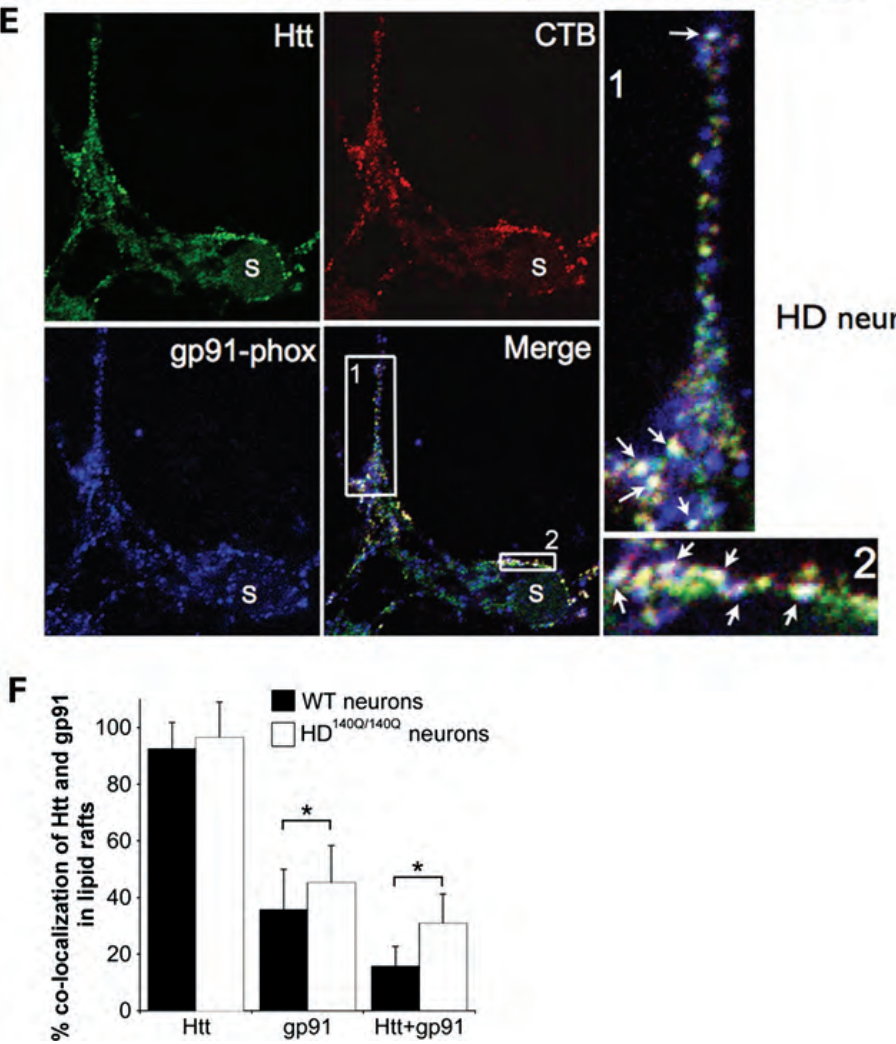

Figure 7. Western blot analysis of gp91-phox in WT and HD ${ }^{140 \mathrm{Q} / 140 \mathrm{Q}}$ mouse brain synaptosomes, and DRMs from primary neurons, and the localization of

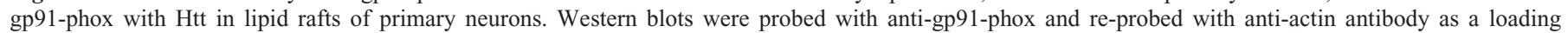

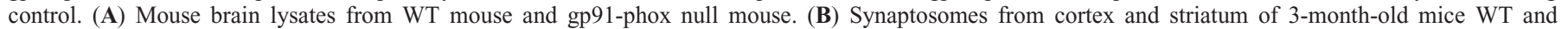


A WT DRM

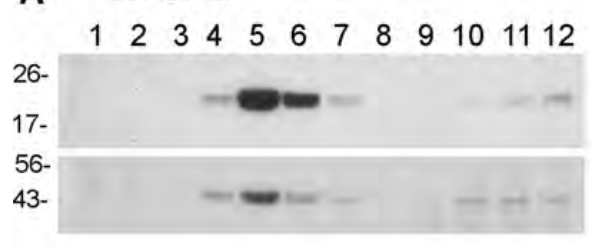

B

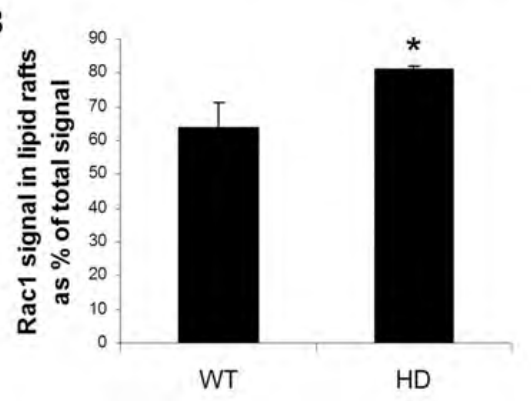

HD DRM

$\begin{array}{lllllllllllll}1 & 2 & 3 & 4 & 5 & 6 & 7 & 8 & 9 & 10 & 11 & 12\end{array}$
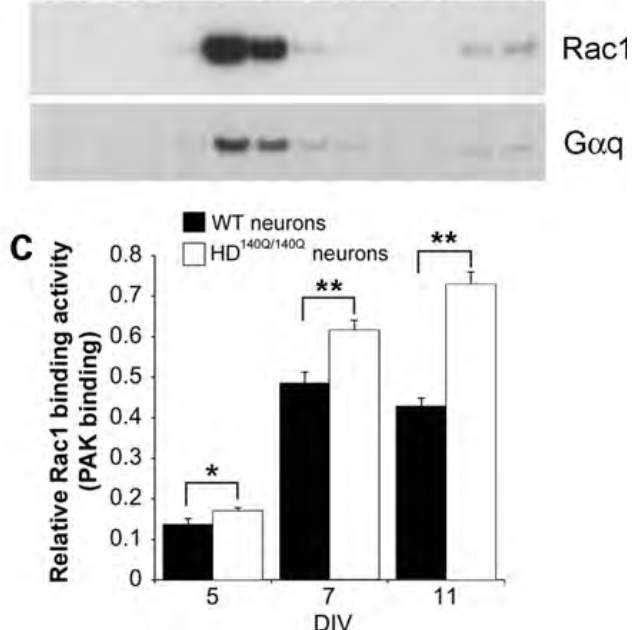

Figure 8. Rac1 is present in lipid rafts and binding activity is increased in $\mathrm{HD}^{140 \mathrm{Q} / 140 \mathrm{Q}}$ neurons. (A) Western blot analysis of Rac1 in DRM of primary WT and $\mathrm{HD}^{140 \mathrm{Q} / 140 \mathrm{Q}}$ neurons. DRMs were prepared from WT and $\mathrm{HD}^{140 \mathrm{Q} / 140 \mathrm{Q}}$ primary neuronal cultures grown to 8 DIV as described in Materials and Methods and subcellular fractions were examined by SDS-PAGE and western blot. Western blots were probed with anti-Rac1 antibody and re-probed with anti-Goq, a lipid raft marker to identify the lipid raft fractions. Sample blots are from one of the three fractionation studies. (B) Bar graph shows the distribution of Rac1 levels in lipid raft fractions relative to the total signal in all fractions as significantly higher in HD fractions $[80.9 \pm 0.92 \%$ for $\mathrm{HD}$ and $63.9 \pm 7.11 \%$ for $\mathrm{WT}$, three independent fractionations, Student's $t$-test, ${ }^{*} P<0.05$. Note: the distribution of G $\alpha \mathrm{q}$ was not different (WT neurons $38.94 \pm 10.28 \%$, HD ${ }^{140 \mathrm{Q} / 140 \mathrm{Q}}$ neurons $48.3 \pm 15.38 \%$, three independent fractionations, Student's $t$-test, $P=0.43$ )]. (C) Relative Rac1 binding activity (PAK binding) was performed in cortical neurons using a commercial assay kit (see Materials and Methods). Data are plotted as mean \pm SD and were analyzed using Student's $t$-test. Rac1 activity is increased in $\mathrm{HD}^{140 \mathrm{Q} / 140 \mathrm{Q}}$ neurons compared with WT neurons at 5,7 and $11 \mathrm{DIV}(* * P<0.001) .5 \mathrm{DIV}: \mathrm{WT} 0.136 \pm 0.015 \mathrm{HD} 0.17 \pm 0.008, n=4$. ${ }^{*} P<0.01,7$ DIV: WT $0.485 \pm 0.028$ HD $0.616 \pm 0.024, n=3,{ }^{* *} P<0.001 ; 11$ DIV WT $0.428 \pm 0.021 \mathrm{HD} 0.729 \pm 0.031, n=4$ WT, $3 \mathrm{HD},{ }^{* *} P<0.001$.

\section{Rac1, a regulator of $\mathrm{NOX} 2$, distributes to $\mathrm{HD}^{140 \mathrm{Q} / 140 \mathrm{Q}}$ lipid rafts and has increased binding activity in $\mathrm{HD}^{140 Q / 140 Q}$ neurons}

Active Rac1 is an important regulator of NOX2 activity in non-neuronal and neuronal cells $(60,61)$. Rac-GTP binds to p67-phox and the complex interacts with gp91-phox at lipid rafts $(17,62)$. DRM from primary WT and $\mathrm{HD}^{140 \mathrm{Q} / 140 \mathrm{Q}}$ neuronal cultures were prepared as described previously (15). SDS-PAGE and western blot analysis showed that Rac1 immunoreactivity was codistributed with the lipid raft marker G $\alpha \mathrm{q}$ in lipid raft fractions in $\mathrm{WT}$ and $\mathrm{HD}^{140 \mathrm{Q} / 140 \mathrm{Q}}$ primary neurons (Fig. 8A). The distribution of Rac1 levels in lipid raft fractions relative to the total signal in all fractions was significantly higher in $\mathrm{HD}^{140 \mathrm{Q} / 140 \mathrm{Q}}$ neurons $(17 \%$ higher $)$ than in WT neurons (Fig. 8B). The distribution of Gaq levels in lipid raft fractions relative to total signal was not significantly different in $\mathrm{HD}^{140 \mathrm{Q} / 140 \mathrm{Q}}$ neurons compared with WT neurons. Rac1 binding activity was examined as described in Materials and Methods using primary WT and $\mathrm{HD}^{140 \mathrm{Q} / 140 \mathrm{Q}}$ cultures of 5, 7 and 11 DIV. The mean level of relative Racl binding activity was significantly higher in $\mathrm{HD}^{140 \mathrm{Q} / 140 \mathrm{Q}}$ primary cortical neurons at 5, 7, and 11 DIV compared with WT neurons (Fig. 8C). Significantly, the rise in Rac1 binding activity at 5 DIV in $\mathrm{HD}^{140 \mathrm{Q} / 140 \mathrm{Q}}$ neurons preceded the detection of an increase in NOX activity and ROS levels at 8 DIV (Figs 1 and 3). These findings suggest that increased Rac1 binding activity at lipid rafts in $\mathrm{HD}^{140 \mathrm{Q} / 140 \mathrm{Q}}$ neurons might account for increased NOX2 activity and ROS levels in HD.

\section{Deletion of NOX2 (gp91-phox) prevents excess ROS production and attenuates cell death in $\mathrm{HD}^{140 \mathrm{Q} / 140 \mathrm{Q}}$ primary neurons}

Our data suggested that increased NOX2 activity is a main source of oxidative stress and cell death in $\mathrm{HD}^{140 \mathrm{Q} / 140 \mathrm{Q}}$ neurons. To validate the involvement of NOX2 in HD pathology, we compared cortex and primary cortical neurons from WT and $\mathrm{HD}^{140 \mathrm{Q} / 140 \mathrm{Q}}$ mice to $\mathrm{HD}^{140 \mathrm{Q} / 140 \mathrm{Q}}$ mice with

$\mathrm{HD}^{140 \mathrm{Q} / 140 \mathrm{Q}}$ mice show gp91-phox migrating at $67 \mathrm{kDa}$. Blot was probed with anti- $\beta$-actin antibody as loading control. (C) DRMs were prepared from primary cortical neurons at 8 DIV as described in Materials and Methods and previously (15). DRM fractions 5-6 contain the lipid raft marker G 2 q and also express gp91-phox in both WT and $\mathrm{HD}^{140 \mathrm{Q} / 140 \mathrm{Q}}$ samples. There was no difference in levels of gp91-phox in lipid raft fractions 5 and 6 relative to total DRM fractions between WT and $\mathrm{HD}^{140 \mathrm{Q} / 140 \mathrm{Q}}$ neurons $(\mathrm{WT}=46.6 \pm 7.1 \%$ and $\mathrm{HD}=50.8 \pm 23.1 \%, P=0.7, n=5$ DRM fractionation experiments per group). (D and E) Localization of cholera toxin subunit-B (CTB) to lipid rafts was performed first in living neurons and then neurons were fixed without permeabilizing and examined for immunohistochemical localization of gp91-phox. Confocal images of WT cortical neuron (D) and HD ${ }^{140 Q / 140 Q}$ cortical neurons (E) labeled at 8 DIV with fluorescent (CTB) in red for lipid rafts, in blue for gp91-phox and in green for Htt. Images show gp91-phox and Htt overlapping with CTB labeling in both WT and $\mathrm{HD}^{140 \mathrm{Q} / 140 \mathrm{Q}}$ neurons. Boxed regions are enlarged at the right. Arrows indicate sites of colocalization of gp91-phox, Htt and CTB (white puncta). S indicates the soma of the neuron. (F) Quantitative analysis of images was performed as described in Materials and Methods. Bar graph shows percent \pm SD of immunoreactive puncta that colocalize gp91-phox and CTB puncta (WT $=35.6 \pm 14.4 \%, \mathrm{HD}=45.2 \pm 13.2 \%, n=56$ neurons, Student's $t$-test, $* P<$ 0.037 ), and the colocalization of Htt and gp91-phox with $\mathrm{CTB}$ puncta (WT $=15.6 \pm 7.2 \%, \mathrm{HD}=31.3 \pm 10.6 \%, n=56$ neurons, ${ }^{*} P<0.021$ ). 
A

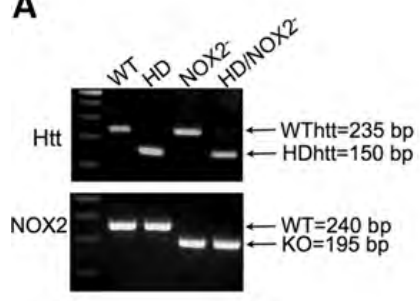

B

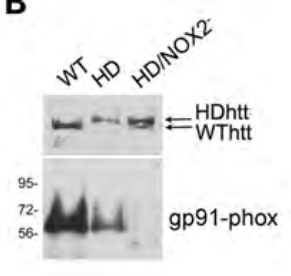

C

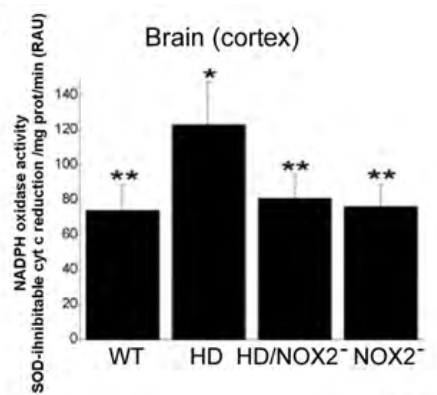

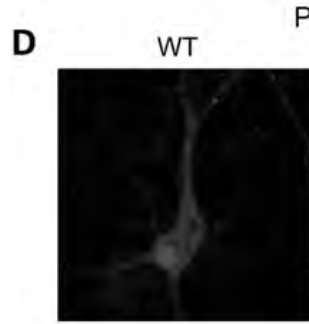

Primary cortical neurons

HD/NOX2-
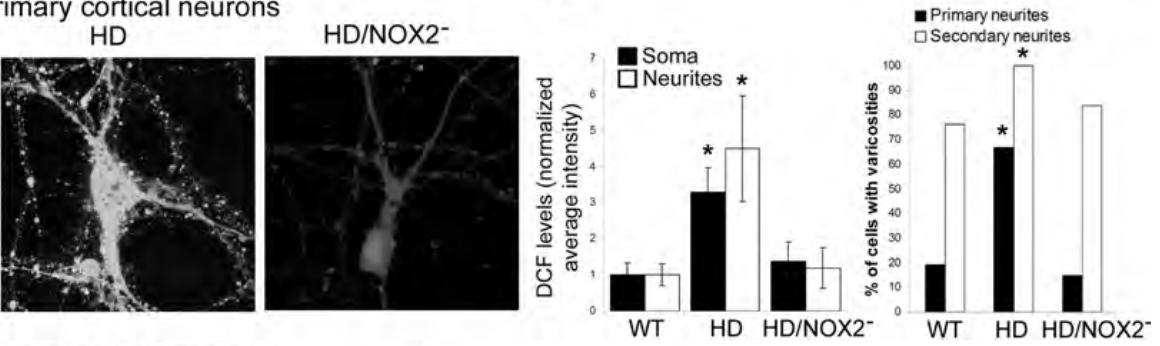

E

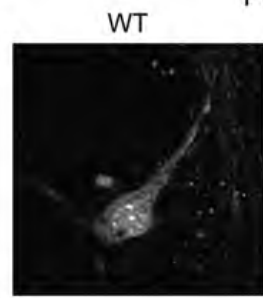

Primary cortical neurons

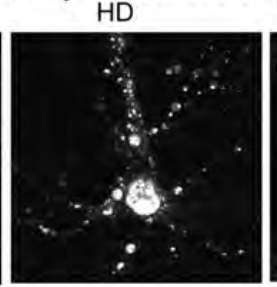

HD/NOX2-
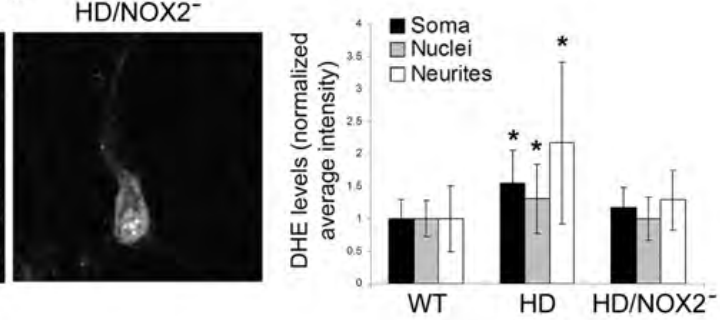

$\mathbf{F}$

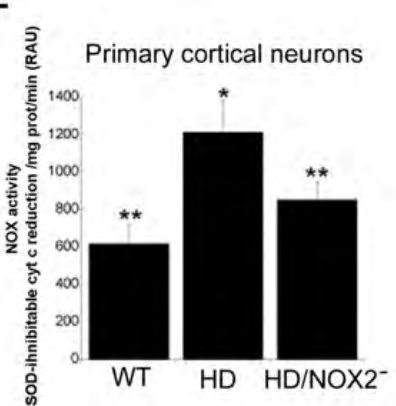

G

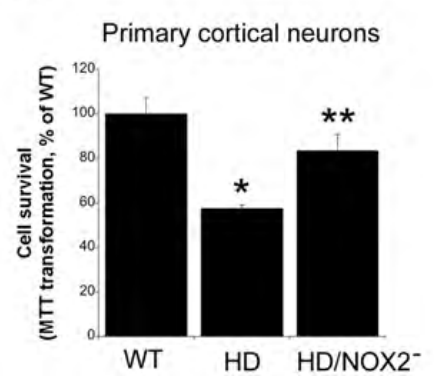

Figure 9. Knocking-out gp91-phox protects $\mathrm{HD}^{140 \mathrm{Q} / 140 \mathrm{Q}}$ neurons from elevated ROS, increased NOX activity and cell death. (A) HD ${ }^{140 \mathrm{Q} / 140 \mathrm{Q}}$ mice were crossed to NOX2 ${ }^{-}$mice to obtain HD/NOX2 ${ }^{-}$as described in Materials and Methods. PCR assay was performed using tails as source of DNA and PCR products were run in agarose gel shown here. Indicated are the sizes of DNA bands expected if genes for WT or mutant Htt and gp91-phox genes are present. (B). Western blots of cortical lysates probed with anti-Htt and anti-gp91-phox antibodies. HD/NOX2 ${ }^{-}$mice do not express gp91-phox protein. (C) NOX activity was determined based on measurement of SOD-inhibitable cytochrome $\mathrm{C}$ reduction as described in Materials and Methods. NOX activity in HD/NOX2 ${ }^{-}$cortex is comparable with the cortex of WT and NOX2 ${ }^{-}$mice and significantly lower than in $\mathrm{HD}^{140 \mathrm{Q} / 140 \mathrm{Q}}$ cortex. Student's $t$-test ${ }^{*} P<0.007$ versus untreated WT neurons $(n=3)$; ${ }^{* *} P<0.003$ versus untreated $\mathrm{HD}^{140 \mathrm{Q} / 140 \mathrm{Q}}$ neurons $(n=4)$. (D) Images of DCF fluorescence in primary cortical neurons from WT, HD ${ }^{140 \mathrm{Q} / 140 \mathrm{Q}}$ and $\mathrm{HD}$ NOX2 $2^{-}$mice. Bar graph shows mean \pm SD intensity of DCF fluorescence in somata and neurites. Data are normalized to WT neurons $(n=42)$. Average DCF fluorescence in $\mathrm{HD}^{140 \mathrm{Q} / 140 \mathrm{Q}}$ neurons $(n=48)$ is elevated and in $\mathrm{HD} / \mathrm{NOX} 2^{-}$neurons $(n=61)$ is comparable with WT (Soma: WT $1.00 \pm 0.34$, HD $3.28 \pm 0.69, \mathrm{HD} / \mathrm{NOX}^{-} 1.37 \pm 0.55^{*} P<1.5 \times 10^{-33}$ compared with WT neurons; neurites: WT $1.00 \pm 0.31, \mathrm{HD} 4.50 \pm 1.46, \mathrm{HD} / \mathrm{NOX} 2^{-} 1.20 \pm .056$, ${ }^{*} P<1.8 \times 10^{-26}$ compared with WT neurons). Right bar graph depicts the percent of neurons with varicosities in primary and secondary neurites. More $\mathrm{HD}^{140 \mathrm{Q} / 140 \mathrm{Q}}$ neurons have varicosities than do WT neurons or HD/NOX2 ${ }^{-}$neurons. $\chi^{2},{ }^{*} P<0.003$ for $\mathrm{HD}^{140 \mathrm{Q} / 140 \mathrm{Q}}$ neurons $(n=48)$ compared with $\mathrm{WT}$ neurons $(n=42)$ and compared with $\mathrm{HD} / \mathrm{NOX}^{-}$neurons $(n=61)$. (E) Images of DHE fluorescence in primary cortical neurons from WT, HD ${ }^{140 \mathrm{Q} / 140 \mathrm{Q}}$ and $\mathrm{HD} / \mathrm{NOX}^{-}$mice. Bar graph shows mean intensity of DHE fluorescence in somata and neurites. Data are normalized to WT neurons $(n=15)$. Average DHE fluorescence in $\mathrm{HD}^{140 \mathrm{Q} / 140 \mathrm{Q}}$ neurons $(n=28)$ is elevated and in $\mathrm{HD} / \mathrm{NOX} 2^{-}$neurons $(n=52)$ is comparable with WT (Soma: WT $1.00 \pm 0.29$, HD $1.54+0.51, \mathrm{HD} / \mathrm{NOX}^{-} 1.18+0.29$; Nuclei: WT $1.00 \pm 0.27, \mathrm{HD} 1.31 \pm 0.53, \mathrm{HD} / \mathrm{NOX}^{-} 1.00 \pm 0.33$; Neurites: WT $1.00 \pm 0.50, \mathrm{HD} 2.17 \pm 1.25$, HD/NOX2 ${ }^{-} 1.29 \pm 0.46,{ }^{*} P<0.05$ compared with WT neurons). (F) NOX activity was determined in lysates of primary cortical neurons using measurement of SOD-inhibitable cytochrome $\mathrm{c}$ reduction as described in Materials and Methods. NOX activity in HD/NOX2 ${ }^{-}$neurons is comparable with that of WT and NOX2 ${ }^{-}$neurons and significantly lower than $\mathrm{HD}^{140 \mathrm{Q} / 140 \mathrm{Q}}$ neurons. Student's $t$-test ${ }^{*} P<0.01(n=3$, triplicate samples in three experiments) versus WT neurons $(n=3) ;{ }^{* *} P<0.03$ versus $\mathrm{HD}^{140 \mathrm{Q} / 140 \mathrm{Q}}$ neurons). (G) Neuron survival was determined at $10 \mathrm{DIV}$ using the MTT assay as described in Materials and Methods. Mean $\pm \mathrm{SD}$ percent MTT transformation for $\mathrm{HD}$ and $\mathrm{HD} / \mathrm{NOX}^{-}{ }^{-}$is shown normalized to WT. Student's $t$-test, ${ }^{*} P<1.3 \times 10^{-13}$ versus WT neurons and ${ }^{* *} P<$ $5.6 \times 10^{-6} \mathrm{HD} / \mathrm{NOX}^{-}$versus $\mathrm{HD}^{140 \mathrm{Q} / 140 \mathrm{Q}}$ neurons, $n=12$ samples from three independent cultures. 
deletion of the gene encoding the catalytic subunit of NOX2 (gp91-phox) (HD/NOX2 ${ }^{-}$mice). The genotypes of the pregnant mice that were used as the source of embryos in these experiments were verified by polymerase chain reaction (PCR) analysis (Fig. 9A) and protein expression for $\mathrm{Htt}$ and gp91-phox were determined from brain lysates by western blot assay (Fig. 9B). Next we examined NOX activity in the cortices of mice that were used as sources of primary neurons. As shown by Pollock et al. (63) and discussed by Altenöfer et al. (54), NOX activity can be detected in $\mathrm{NOX}^{-}$mice and may arise from the activity of NOX1 and NOX4 enzymes; similarly, NOX4 null mice can exhibit basal NOX activity from NOX1 or NOX2. NOX activity in $\mathrm{HD} / \mathrm{NOX}^{-}$cortex was significantly lower than in $\mathrm{HD}^{140 \mathrm{Q}}$ $140 \mathrm{Q}$ cortex and did not differ from levels in cortex of WT or $\mathrm{NOX}^{-}$mice (Fig. 9C). Cortical cultures were evaluated at 8 DIV for ROS levels using DCF and DHE fluorescences. Fluorescence intensity in somata and neurites of $\mathrm{HD} / \mathrm{NOX} 2^{-}$ neurons was lower than in $\mathrm{HD}^{140 \mathrm{Q} / 140 \mathrm{Q}}$ neurons and more comparable with the levels in WT neurons (Fig. 9D and E). Quantitative analysis confirmed that the mean signal intensities for DCF and DHE in $\mathrm{HD} / \mathrm{NOX}^{-}$neurons were significantly lower than in $\mathrm{HD}^{140 \mathrm{Q} / 140 \mathrm{Q}}$ neurons and did not differ from WT neurons (bar graphs, Fig. 9D and E). Thus ROS levels as detected by the presence of DCF or DHE were restored to normal levels in $\mathrm{HD}^{140 \mathrm{Q} / 140 \mathrm{Q}}$ neurons devoid of gp91-phox. As expected, NOX activity in $\mathrm{HD} / \mathrm{NOX}^{-}$ samples was significantly lower than in $\mathrm{HD}^{140 \mathrm{Q} / 140 \mathrm{Q}}$ primary cortical neurons and comparable with the levels in WT primary neurons and cortex (Fig. 9F). Finally, we asked whether attenuation of NOX activity by removal of gp91-phox protected $\mathrm{HD}^{140 \mathrm{Q} / 140 \mathrm{Q}}$ neurons from cell death. By MTT assay, the viability of $\mathrm{HD} / \mathrm{NOX}^{-}$neurons was significantly increased compared with $\mathrm{HD}^{140 \mathrm{Q} / 140 \mathrm{Q}}$ neurons and did not differ from WT neurons (Fig. 9G). These data suggest that modulating NOX2 activity by deletion of gp91-phox is neuroprotective for $\mathrm{HD}^{140 \mathrm{Q} / 140 \mathrm{Q}}$ neurons.

\section{Rise of mitochondrial superoxide in $\mathrm{HD}^{140 \mathrm{Q} / 140 \mathrm{Q}}$ neurons follows increase in NOX activity}

Our data show that a nonmitochondrial source of superoxide may arise from NOX2 activity in $\mathrm{HD}^{140 \mathrm{Q} / 140 \mathrm{Q}}$ cortical and striatal neurons. Mitochondria are considered a main contributor of excess ROS and neurotoxicity in HD. To determine the contribution of superoxide from mitochondria to toxicity of $\mathrm{HD}^{140 \mathrm{Q} / 140 \mathrm{Q}}$ primary cortical neurons, we incubated neurons with MitoSox (Invitrogen), which is taken up by mitochondria and fluoresces in the presence of superoxide. MitoSox fluorescence is diffuse in resting mitochondria and increased in smaller and larger clumps of mitochondria in stressed neurons (Fig. 10). Images of WT and $\mathrm{HD}^{140 \mathrm{Q} / 140 \mathrm{Q}}$ primary cortical neurons revealed MitoSox fluorescence increased in $\mathrm{HD}^{140 \mathrm{Q} / 140 \mathrm{Q}}$ neurons at $10 \mathrm{DIV}$ but not at 8 DIV (Fig. 10A). Quantitative analysis confirmed that the mean \pm SD intensity of MitoSox fluorescence was significantly increased in $\mathrm{HD}^{140 \mathrm{Q} / 140 \mathrm{Q}}$ neurons compared with WT neurons (Student's $t$-test, $P<0.0006, n=31$ WT neurons and 42 HD neurons). Thus the rise in ROS in mitochondria at 10 DIV follows the rise in NOX activity detected at 8 DIV. The percent of total
$\mathrm{HD}^{140 \mathrm{Q} / 140 \mathrm{Q}}$ neurons with large fluorescent puncta indicative of abnormal mitochondria was increased at 10 DIV (Fig. 10B) coinciding with a time when cell death is measurable by the MTT assay. Treating $\mathrm{HD}^{140 \mathrm{Q} / 140 \mathrm{Q}}$ neurons at 5 DIV with MitoQ $(0.5-2 \mathrm{nM})$, which is an antioxidant that targets to mitochondria, did not improve cell viability at 10 DIV (Fig. 10C). These data suggest that excess superoxide generated by mitochondria is not a main source of ROS contributing to cell death in $\mathrm{HD}^{140 \mathrm{Q} / 140 \mathrm{Q}}$ neurons.

\section{DISCUSSION}

NOX activity is an important generator of ROS that modulates signaling pathways in non-neuronal and neuronal cells $(17,20,32,34,36,37)$. We found higher than normal levels of NOX activity in the postmortem brain of human HD patients compared with controls and in brain of a knock-in mouse model of $\mathrm{HD}\left(\mathrm{HD}^{140 \mathrm{Q} / 140 \mathrm{Q}}\right)$ compared with WT mice. The highest activity in human HD brain was detected in tissue of two patients who were presymptomatic with Grade 1 striatal pathology at the time of death. Consistent with results in human $\mathrm{HD}$ brain, the brain of $\mathrm{HD}^{140 \mathrm{Q} / 140 \mathrm{Q}}$ mice had elevated NOX activity in synaptosome fractions and the increase was significant in 3-month-old mice. NOX activity was most elevated in striata of 6 -month-old $\mathrm{HD}^{140 \mathrm{Q} / 140 \mathrm{Q}}$ mice. $\mathrm{HD}^{140 \mathrm{Q} / 140 \mathrm{Q}}$ mice at this age consistently exhibit motor deficits and neuropathology of the striatum $(42,43)$. Synaptosomes are enriched with pre- and postsynaptic membranes and may be a major source of the NOX activity in $\mathrm{HD}^{140 \mathrm{Q} / 140 \mathrm{Q}}$ neurons. Consistent with a pathogenic role at synapses, there was more NOX activity in synaptosomes from $\mathrm{HD}^{140 \mathrm{Q} / 140 \mathrm{Q}}$ mouse striatum, the region most affected in $\mathrm{HD}$, than in synaptosomes from $\mathrm{HD}^{140 \mathrm{Q} / 140 \mathrm{Q}}$ mouse cortex.

We found that the enhanced NOX activity and ROS levels were detected in $\mathrm{HD}^{140 \mathrm{Q} / 140 \mathrm{Q}}$ primary neurons before evidence of cell death. NOX activity achieved comparable high levels in $\mathrm{HD}^{140 \mathrm{Q} / 140 \mathrm{Q}}$ striatal and cortical neurons at 8 DIV. However, striatal neurons had a slower rise in cell death compared with cortical neurons. It is possible that striatal neurons derived from neonatal brains handle ROS better than cortical neurons derived from embryonic brain. The cell death in both neuron types clearly involved a rise in NOX activity. Treating $\mathrm{HD}^{140 \mathrm{Q} / 140 \mathrm{Q}}$ primary cortical and striatal neurons with NOX inhibitors, including one selective for NOX2 that was tested in cortical neurons, reduced NOX activity and ROS levels and increased neuronal viability. Importantly, primary cortical HD neurons with a deletion of the catalytic subunit of NOX2 were protected from elevated NOX activity, ROS and cell death. Thus NOX2 is likely to be the primary source of elevated NOX activity in $\mathrm{HD}^{140 \mathrm{Q} / 140 \mathrm{Q}}$ neurons. Moreover, our data suggest that it is the early rise in superoxide from excess NOX2 activation and not from the dysfunction of mitochondria that contributes to $\mathrm{HD}^{140 \mathrm{Q} / 140 \mathrm{Q}}$ neuronal death. Altogether, our findings strongly support a pathogenic role of NOX2 activation in HD.

Oxidative damage to cytoskeletal proteins and membrane constituents can impair the transport of organelles and vesicle cargo to dendrites and axons and change neuronal morphology by forming dystrophic neurites $(64,65)$. Excess $\mathrm{H}_{2} \mathrm{O}_{2}$ is known to damage neuronal membranes resulting in 
A
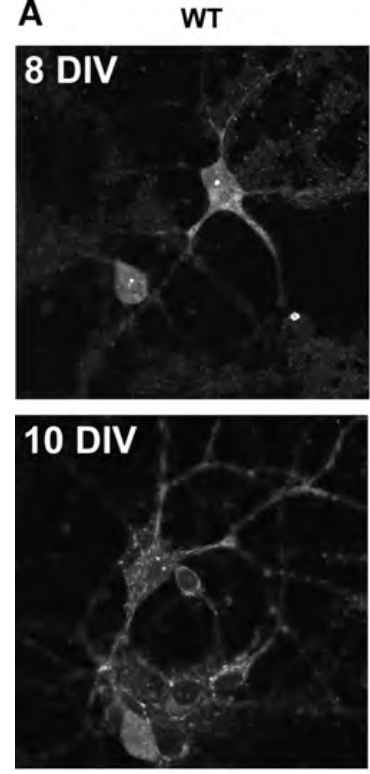
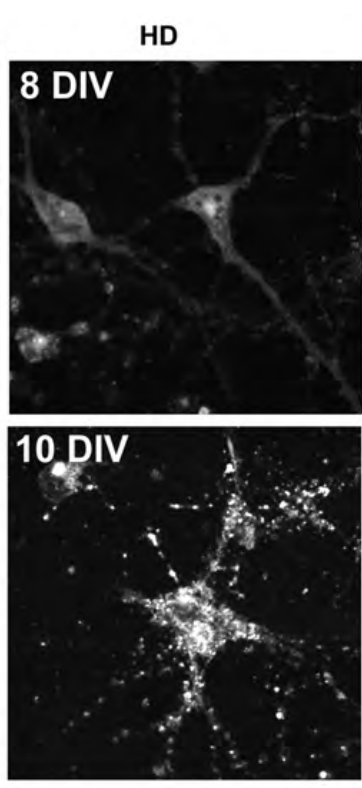

B
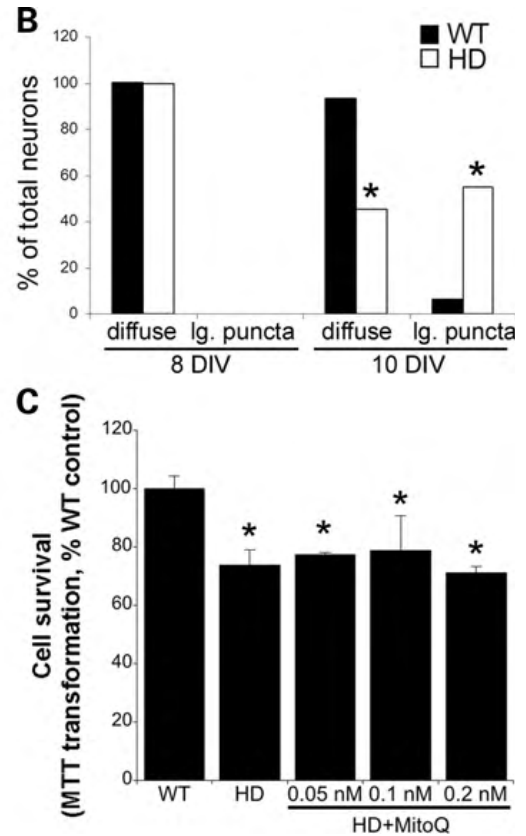

Figure 10. Contribution mitochondrial ROS to the death of $\mathrm{HD}^{140 \mathrm{Q} / 140 \mathrm{Q}}$ neurons. (A) WT and $\mathrm{HD}^{140 \mathrm{Q} / 140 \mathrm{Q}}$ cortical neurons were treated with MitoSox, an ROS indicator that targets to mitochondria and evaluated as described in Materials and Methods. Representative images show MitoSox fluorescence increased in $\mathrm{HD}^{140 \mathrm{Q} / 140 \mathrm{Q}}$ neurons at $10 \mathrm{DIV}$. (B) Bar graph shows percent of total neurons with MitoSox fluorescence appearing as diffuse small punctate label (small mitochondria) and as large puncta (large or clustered mitochondria). No large puncta were observed in WT or $\mathrm{HD}^{140 \mathrm{Q} / 140 \mathrm{Q}}$ neurons at 8 DIV. $\chi^{2}$ test, ${ }^{*} P<0.0001$ $\mathrm{HD}^{140 \mathrm{Q} / 140 \mathrm{Q}}$ neurons versus WT neurons. (C) Bar graph shows mean \pm SD percent of MTT transformation normalized to WT in $\mathrm{HD}^{140 \mathrm{Q} / 140 \mathrm{Q}}$ cortical neurons that were untreated or treated with the antioxidant MitoQ which targets to mitochondria. Student's $t$-test, ${ }^{*} P<0.001$ versus WT neurons.

lowered $\mathrm{pH}$ and altered activity of ion channels (66). We speculate that chronic oxidative stress arising from increased NOX2 activity could contribute to some of the alterations in vesicle transport and synaptic function observed in cell and animal models of HD (67-71).

The appearance of highly varicose neurites with elevated ROS detected by DCF and DHE fluorescence in $\mathrm{HD}^{140 \mathrm{Q} / 140 \mathrm{Q}}$ primary neurons may be directly related to the production of NOX activity. Swellings can form in neurons in vitro in response to oxidative stress $(72,73)$. HD exon-1 expressed in primary hippocampal neurons caused neurites to develop excessive swellings, suggesting that mutant $\mathrm{Htt}$ leads to changes in morphology of neuronal processes (74). Consistent with our recent findings in WT neurons (44), we found neurite swellings increased in both WT neurons and $\mathrm{HD}^{140 \mathrm{Q} / 140 \mathrm{Q}}$ cortical neurons treated with $\mathrm{H}_{2} \mathrm{O}_{2}$ supporting a role for endogenously generated $\mathrm{H}_{2} \mathrm{O}_{2}$ in altering the morphology of $\mathrm{HD}$ neurons. Morphological changes in Htt immunoreactive cortical and striatal neurons are seen in HD postmortem brain, including the presence of atypical large axonal swellings (75) and dystrophic neurites with irregular shapes reminiscent of degenerating neurites (69).

Our data in neuronal-enriched cultures suggest that neurons are a major source of NOX activity in the HD brain. However, other cell types in the brain cannot be ruled out. NOX activity increases in microglia following traumatic injury to nervous tissue and contributes to ROS formation $(76,77)$. Since reactive microglia occur in the HD patient brain (78), these cells may be a source of excess NOX activity and ROS. However, reactive microglia increase in the HD postmortem brain with advancing disease (78), whereas the NOX activity that we detected in human brain was highest in lower grade presymptomatic HD.

How mutant Htt affects NOX activity is unclear. Gp91-phox colocalized with mutant Htt more than with WT Htt at plasma membrane lipid rafts. The abundance and/or proximity of mutant Htt to gp91-phox could influence the catalytic activity. In contrast to a previous report by another group showing interaction of a polyglutamine peptide with gp91-phox (40), we did not find that endogenous $\mathrm{Htt}$ interacts with gp91-phox by immunoprecipitation assay using brain lysates (results not shown). In human neutrophils, active Rac G proteins (isoforms 1 and 2) associate with p67-phox and this complex interacts with gp91-phox at lipid rafts to modulate the activation of NOX (79). An interaction between the Nterminal region of mutant Htt encoded by exon 1 and Rac1 has been reported (80) and may underlie the increase in Rac1 activity observed in $\mathrm{HD}^{140 \mathrm{Q} / 140 \mathrm{Q}}$ neurons. Alternatively, mutant Htt may interfere with the stability of the assembled NOX complex or with phosphorylation of one of the subunits in a way that alters kinetics of disassembly. In phagocytes, the cytosolic component $\mathrm{p} 47$-phox requires binding to phosphatidylinositol 3-phosphates PI(3)P and PI $(3,4) \mathrm{P} 2$ at the plasma membrane to stabilize the localization to gp91-phox and p22-phox (19). We have shown that WT and mutant Htt interact with $\mathrm{PI}(3,4) \mathrm{P} 2$ and mutant $\mathrm{Htt}$ but not WT Htt interacts with $\mathrm{PI}(3) \mathrm{P}$ (81). Thus mutant $\mathrm{Htt}$ interactions with $\mathrm{PI}(3) \mathrm{P}$ and $\mathrm{PI}(3,4) \mathrm{P} 2$ at the plasma membrane could play a role in the stability of NOX complex assembly.

In a previous study, we showed that $\mathrm{HD}^{140 \mathrm{Q} / 140 \mathrm{Q}}$ primary cortical neurons have a deficient antioxidant system. The levels of glutathione, a major antioxidant, are lower in 
$\mathrm{HD}^{140 \mathrm{Q} / 140 \mathrm{Q}}$ neurons compared with WT neurons and treating $\mathrm{HD}^{140 \mathrm{Q} / 140 \mathrm{Q}}$ neurons with $N$-acetyl-cysteine which increases the levels of glutathione is neuroprotective (45). Thus $\mathrm{HD}^{140 \mathrm{Q} / 140 \mathrm{Q}}$ neurons have two nonmitochondrial factors contributing to ROS production, high ROS generated by NOX activity and deficient handling of excess ROS by the glutathione antioxidant system. Therapeutic approaches to reduce oxidative damage in HD patients are in progress (82). Treatments that address nonmitochondrial sources of oxidative stress in HD may have benefit.

\section{MATERIALS AND METHODS}

\section{Mouse and human brain tissue}

WT and HD mice (C57BL/6 strain background) are maintained at the $\mathrm{MGH}$ animal facility. $\mathrm{HD}^{140 \mathrm{Q} / 140 \mathrm{Q}}$ mice have an insert of 140 CAGs in the Htt gene (42). Homozygous mice were obtained by mating homozygous male with homozygous female mice, and the genotype was confirmed by PCR analysis.

NOX2 knock-out $\left(\mathrm{NOX}_{2}^{-}\right)$mice were obtained from The Jackson Laboratory (B6.129S-Cybb ${ }^{\text {tm1Din }} / \mathrm{J}$, stock 002365). $\mathrm{NOX}^{-}$mice (C57BL/6J background strain) are homozygote-hemizygote (female-male) for chronic granulomatous disease (CGD) and have a defective respiratory burst oxidase arising from a null allele of the X-linked gene that encodes the $91 \mathrm{kDa}$ subunit of NOX2 (gp91-phox). NOX2 ${ }^{-}$ mice are normal breeders, produce litters of $8-10$ pups with no developmental problems and mature similarly to WT animals. NOX2 ${ }^{-}$mice were crossed with $\mathrm{HD}^{140 \mathrm{Q} / 140 \mathrm{Q}}$ mice to obtain $\mathrm{HD}^{140 \mathrm{Q} / 7 \mathrm{Q}} / \mathrm{NOX} 2^{-/+}$mice, which were then backcrossed with $\mathrm{HD}^{140 \mathrm{Q} / 140 \mathrm{Q}}$ and NOX2 ${ }^{-}$mice. Finally, homozygous HD/null gp91-phox mice were obtained, which are here referred to as $\mathrm{HD} / \mathrm{NOX}^{-}{ }^{-}$. Analysis by PCR in the same DNA samples confirmed the presence of two HD alleles (homozygote) and the absence of gp91-phox. Genotype results were confirmed by SDS-PAGE and western blot analysis showing the absence of the gp91-phox protein and the presence of mutant $\mathrm{Htt}$ in the $\mathrm{HD} / \mathrm{NOX}^{-}$mice (Fig. 9). Intercrosses of the HD/NOX2 ${ }^{-}$mice produced pregnant females that provided embryos as the source of primary cortical neurons as described subsequently.

The animal protocol was reviewed and approved by the MGH Subcommittee on Research Animal Care (SRAC)OLAW Assurance \# A3596-01. The protocol conforms to the USD Animal Welfare Act, PHS Policy on Humane Care and Use of Laboratory Animals, the 'ILAR Guide for the Care and Use of Laboratory Animals' and other applicable laws and regulations.

Human control and HD frozen brain tissue was obtained from the Department of Neurology, Massachusetts General Hospital and the Neuropathology Core of the Massachusetts Alzheimer Disease Research Center (P50 AG05134).

\section{Primary neuronal cultures and drug treatments}

Primary cortical neurons were obtained from brains of embryonic mice (E15-E17) as described before (15), whereas striatal neurons were obtained from neonate mice. Briefly, brains were dissected from embryos and after meninges were removed, cortices or striata were incubated at $37^{\circ} \mathrm{C}$ for $15 \mathrm{~min}$ with $0.625 \%$ trypsin in Neurobasal media (NBM, supplemented with B27, N2, $500 \mu \mathrm{g} / \mathrm{ml}$ streptomycin, $100 \mathrm{IU} / \mathrm{ml}$ penicillin and $2 \mathrm{~mm}$ L-glutamine, all from Invitrogen, Carlsbad, CA, USA). Trypsin was removed and Dulbecco's Modified Eagle Medium plus nutrient mix F12 (DMEM/F12, Invitrogen) supplemented with $10 \%$ fetal bovine serum (FBS, Invitrogen), N2 supplement and penicillin/streptomycin was added to inactivate the trypsin. Cortices and striata were treated with $12.5 \mu \mathrm{g} / \mathrm{ml}$ DNAse I (Sigma, St. Louis, MO, USA) in DMEM/F12 + FBS for $5 \mathrm{~min}$ at $37^{\circ} \mathrm{C}$ and homogenized. Cell suspension was then diluted in NBM supplemented with $25 \mu \mathrm{M} \mathrm{L}$-glutamate and $10 \mu \mathrm{M} 2-\beta$ mercaptoethanol (Invitrogen). Neurons were plated at 800000 cells/ml for biochemical analysis and at 200000 cells/ml for imaging analysis in culture dishes pre-coated with poly-L-lysine (PLL, 30$70 \mathrm{kDa}$ from Sigma) $0.2 \mathrm{mg} / \mathrm{ml}$ in borate buffer $\mathrm{pH} 8.0$ for $24 \mathrm{~h}$ followed by $1 \mathrm{~h}$ coating period with $10 \%$ FBS (DMEM/F12 + FBS). Cytosine $\beta$-D-arabinofuranoside (AraC) was added at 2 DIV for $24 \mathrm{~h}$, and then media was completely replaced with fresh NBM. Half of the volume of medium was replaced every third day. The density of immunoreactive cells positive for $\beta$-III tubulin (a neuronal marker), GFAP (a marker of astrocytes) and cd68 (a marker for microglia) was performed at 5-8 DIV. Results showed that the majority of cells $(>99.5 \%)$ were positive only for $\beta$-III tubulin.

Treatment with NOX inhibitors was carried out in 24- and 48-well plates with 400000 and 200000 neurons per well, respectively. Neurons were treated once with a single dose at 5 DIV of inhibitors of NOX, DPI (0.1 $\mu \mathrm{M}$, Sigma), APO (50 $\mu \mathrm{M}$, Sigma) or VAS2870 (10 $\mathrm{MM}$, Millipore $)$ and superoxide quencher EUK189 (5 $\mu \mathrm{M}$, Dalton Pharma Services, Toronto, Ont., Canada). Some cultures were treated with $100 \mu \mathrm{M}$ $\mathrm{H}_{2} \mathrm{O}_{2}$ for 10 min following published methods $(52,53)$ and then evaluated for ROS levels as described subsequently.

\section{Measurement of ROS in living neurons}

Primary cortical and striatal WT and $\mathrm{HD}^{140 \mathrm{Q} / 140 \mathrm{Q}}$ neurons were plated to a density of $200000 \mathrm{cell} / \mathrm{ml}$ on glass coverslips (25 $\mathrm{mm}$ in diameter) in 6-well plates previously coated overnight with PLL and DMEM/F12 + FBS as described above. Living cells were used for measuring ROS as previously described (83). At $8 \mathrm{DIV}$, neurons were incubated with $2 \mu \mathrm{M}$ carboxy-DCFDA-AM (Invitrogen) at $37^{\circ} \mathrm{C}$ for $30 \mathrm{~min}$. In other experiments, neurons were incubated with $2 \mu \mathrm{M}$ DHE at $37^{\circ} \mathrm{C}$ for $30 \mathrm{~min}$. Neurons were washed three times with pre-warmed PBS to discard excess dye. Coverslips with DCFDA-loaded neurons were mounted in a stage top incubation system INU-NI-F1 (Tokai Hit Co.) with controlled temperature at $37^{\circ} \mathrm{C}$. Images of live neurons were obtained using a Bio-Rad Radiance 2100 confocal laser-scanning microscope with krypton-argon laser. Images were acquired through a $\times 60$ oil immersion Nikon Apo objective DIC $\mathrm{H}$ $(\mathrm{NA}=1.4)$ on an inverted Nikon Eclipse TE300 fluorescent microscope using $488 \mathrm{~nm}$ excitation and $515 \mathrm{~nm}$ emission wavelengths. After adjustment of focus by clearly visualizing neurites, images were rapidly acquired in order to prevent 
bleaching and avoid artifacts caused by leaking or compartmentalization of the probe. All images in an experiment were captured within $10 \mathrm{~min}$. To be sure that the DCF or DHE signal did not vary within this time period, we exposed cells to UV, and then captured images of the same cells periodically from 1 to $10 \mathrm{~min}$. No difference in DCF or DHE signal was observed in the re-imaged cells (data not shown), which confirmed the stability of the DCF and DHE signal within the recording period. The soma and neurites of individual neurons were manually tracked using $\mathrm{NIH}$ Image-J and the DCF or DHE fluorescent signal was expressed as the mean average intensity per neuron with standard deviation. In some experiments, primary neurons were incubated with $2.5 \mu \mathrm{M}$ of MitoSox (Invitrogen) for $15 \mathrm{~min}$ in NBM at $37^{\circ} \mathrm{C}$ in the dark. Cells were then washed twice with prewarmed PBS and mounted in the live cell imaging chamber. Images were obtained as described above for DCF and DHE experiments. Excitation and emission wavelengths for MitoSox were 510/580 nm.

\section{Cell survival assay (MTT transformation)}

As previously described, cell viability was measured in WT, $\mathrm{HD}^{140 \mathrm{Q} / 140 \mathrm{Q}}$ and $\mathrm{HD} / \mathrm{NOX}^{-}$cortical and striatal neurons using an MTT assay (15). Viable neurons transform MTT into formazan blue crystals. Neurons were incubated with $0.5 \mathrm{mg} / \mathrm{ml}$ MTT in NBM for $15 \mathrm{~min}$ at $37^{\circ} \mathrm{C}$, and formazan blue was dissolved with $100 \%$ DMSO. Detection of the MTT transformation was measured with a spectrophotometer at an excitation wavelength of $540 \mathrm{~nm}$. Neuron survival is proportional to the intensity of blue-purple color in the solution. Results are expressed as the percentage of cell survival normalized to untreated WT neurons.

\section{NOX activity measurements}

NOX activity was measured as the superoxide dismutaseinhibitable cytochrome c reduction by superoxide anion produced by NOX (41). The assay uses exogenous $\mathrm{NADPH}^{+}$ and $\mathrm{FAD}^{+}$to transfer an electron to the catalytic subunit gp91-phox, which will form a superoxide anion. This free radical reduces cytochrome $\mathrm{c}$ and is detected by absorbance at $550 \mathrm{~nm}$ over time. Superoxide dismutase $300 \mathrm{U} / \mathrm{ml}$ (SOD) was used to determine the superoxide anion produced by the NOX assay.

Briefly, primary cortical and striatal neurons at 8 DIV from $\mathrm{WT}, \mathrm{HD}^{140 \mathrm{Q} / 140 \mathrm{Q}}$ and $\mathrm{HD} / \mathrm{NOX}^{-}$mice were harvested in lysis buffer $(150 \mathrm{~mm} \mathrm{KCl}, 150 \mathrm{~mm} \mathrm{NaCl}, 1 \mathrm{~mm} \mathrm{MgCl} 2,1 \mathrm{~mm}$ EGTA, $2 \mathrm{~mm} \mathrm{NaN}$, $1 \mathrm{~mm}$ DTT and protease inhibitors cocktail) plus $2 \%$ glycerol (v/v). Membrane and cytosolic fractions (S2/P2) were separated by centrifugation. Cell homogenates from cytosolic and membrane fractions were mixed (50$100 \mu \mathrm{g}$ protein, respectively), and incubated for $60 \mathrm{~s}$ at $25^{\circ} \mathrm{C}$ in lysis buffer supplemented with $100 \mu \mathrm{M}$ cytochrome c, $10 \mu \mathrm{M} \mathrm{FAD}{ }^{+}$and $100 \mu \mathrm{M}$ SDS. The enzymatic activity was then initiated by the addition of $200 \mu \mathrm{M} \mathrm{NADPH}^{+}$and followed by $5 \mathrm{~min}$ at $25^{\circ} \mathrm{C}$. Results of the NOX activity are expressed as the reduced cytochrome c per milligram protein per minute as relative absorbance units at $550 \mathrm{~nm}$ (RAU at $550 \mathrm{~nm})$. The same protocol was applied to measure the activity of NOX from frozen human brain tissue and synaptosome fractions from mouse brain, however, instead of separating membrane and cytosolic fractions, the whole tissue lysate was used, incubating the homogenate with lysis buffer supplemented with $100 \mu \mathrm{M}$ cytochrome c, $10 \mu \mathrm{M} \mathrm{FAD}^{+}$and $100 \mu \mathrm{M}$ SDS. Total protein levels were obtained by the Bradford assay. All reagents for this experiment were obtained from Sigma.

\section{Measurement of Rac1 binding activity}

Rac1 binding activity was measured using the G-LISA ${ }^{\mathrm{TM}}$ Rac Activation Assay Biochem Kit ${ }^{\mathrm{TM}}$ (Absorbance based, Cytoskeleton, Inc., Denver, CO, USA) according to the recommended protocol. Briefly, cell lysates were subjected to a PAK-pull down assay. PAK is a downstream effector protein that binds directly to active Rac. GTP-bound Rac1 is bound to the well coated with anti-Rac1-specific antibody, and then the inactive Rac1 is removed during the washes in the assay.

\section{SDS-PAGE and western blot analysis of levels of gp91-phox}

The levels of gp91-phox, the membrane associated and catalytic subunit of NOX2, was evaluated by SDS-PAGE and western blot. Samples $(20-40 \mu \mathrm{g})$ of WT, $\mathrm{HD}^{140 \mathrm{Q} / 140 \mathrm{Q}}$ and $\mathrm{HD} / \mathrm{NOX}^{-}$primary cortical and striatal neurons from 3,5 , 8 and 10 DIV, synaptosomes samples from WT and $\mathrm{HD}^{140 \mathrm{Q} / 140 \mathrm{Q}}$ mouse brains, and cortex and striatum from human brain tissue were loaded in SDS-PAGE. The resolved proteins were transferred to nitrocellulose membranes, blocked with $5 \%$ nonfat milk in TBST [Tris buffered saline plus $0.1 \%$ (v/ v) Tween-20] for $1 \mathrm{~h}$. Primary antibody (monoclonal anti-gp91-phox antibody (clone 54.1, Santa Cruz) was diluted 1:100, incubated overnight at $4{ }^{\circ} \mathrm{C}$ and subsequently incubated for $1 \mathrm{~h}$ with horseradish peroxidase-linked secondary antibody. Bands were visualized using SuperSignal West Pico Chemiluminescent substrate from Pierce (Pierce Biotechnology, Rockford, IL, USA). The anti-gp91-phox antibody has been shown previously to be specific for NOX2. In lung tissue from a mouse model with CGD which lacks gp91-phox $\left(\mathrm{NOX}^{-}\right)^{-}$, this antibody failed to express the $\sim 67 \mathrm{kDa}$ gp91-phox product on western blot (84).

\section{Colabeling of gp91-phox and $\mathrm{Htt}$ in lipid rafts in primary cortical neurons}

Lipid rafts were labeled in live primary cortical neurons as described previously (15) using a commercial kit from Invitrogen (Vybrant Alexa Fluor 594 Lipid Raft Labeling kit). The detection of lipid rafts is based on the binding of fluorescent-labeled CTB to ganglioside M1 (GM1), which is mostly located in these membrane domains (34). Briefly, cortical primary neurons at 8 DIV grown on glass coverslips were incubated in complete NBM media containing CTB at $4{ }^{\circ} \mathrm{C}$ in the dark, and then cells were treated with anti-CTB to crosslink the fluorescent-labeled CTB, which allows the formation of larger punctate patterns along the cell membrane where lipid rafts are distributed. Neurons were fixed in fresh $4 \%$ paraformaldehyde (PFA) for $30 \mathrm{~min}$ at $4{ }^{\circ} \mathrm{C}$, blocked for $1 \mathrm{~h}$ at RT in blocking buffer containing 4\% normal goat serum (Jackson 
ImmunoResearch Laboratories, Inc.) in PBS. Cells were then incubated overnight at $4{ }^{\circ} \mathrm{C}$ with anti-gp91-phox (monoclonal anti-gp91-phox antibody 54.1, from Santa Cruz) at 1:100 dilution, and anti-Htt to epitope 1-17 (Ab1) (85) at 1:500 dilution in blocking buffer. Cells were washed three times and incubated with secondary antibodies at a dilution of 1:2000 for $1 \mathrm{~h}$ at RT (Cy5 for gp91-phox, and FITC for $\mathrm{Htt}$ ). After several washes, cells were mounted on a slide using ProLong (Invitrogen). Controls for the immunostaining were omission of the primary antibody for gp91-phox and/or Htt and omission of the secondary antibodies. Colocalization of gp91-phox and Htt in CTB-labeled lipid rafts at the plasma membrane was analyzed in individual neurons using an inverted Leica TCS fluorescent microscope with a Leica TCS SL confocal (krypton-argon) laser-scanning system (Leica Microsystems, Heidelberg, Germany). Images were acquired using LCS software and a $\times 100$ Leica oil immersion objective $(\mathrm{NA}=1.4)$ with $630 / 695-\mathrm{nm}$ excitation-emission for gp91-phox, 495/525-nm excitation-emission for Htt, and 590/617 nm excitation-emission for fluorescent CTB.

\section{Isolation of the synaptosomal fractions}

Synaptosomes from fresh WT and $\mathrm{HD}^{140 \mathrm{Q} / 140 \mathrm{Q}}$ mouse brains were isolated by sucrose gradient centrifugation as previously described by Hajos as a high-purity method to prepare synaptosomal fractions (86). Brain tissue was collected by dissecting the cortex and striatum from WT and $\mathrm{HD}^{140 \mathrm{Q} / 140 \mathrm{Q}}$ mice (3-, 6- and 12-month-old mice) on ice and washed in ice-cold PBS (pH 7.4). The tissue was then homogenized on ice in $7 \mathrm{ml}$ of $0.32 \mathrm{M}$ sucrose plus protease inhibitors and $1 \mathrm{~mm}$ DTT using a Dounce homogenizer (tight piston) by applying 8 strokes per sample. Homogenates were then centrifuged at $4{ }^{\circ} \mathrm{C}$ for $10 \mathrm{~min}$ at $1000 \mathrm{~g}$ to remove cell debris and nuclear material. Then, $6.5 \mathrm{ml}$ of the supernatant was layered onto $6.5 \mathrm{ml}$ of $1.2 \mathrm{M}$ sucrose in $14 \times 89 \mathrm{~mm}$ UltraClear centrifuge tubes (Beckman, Palo Alto, CA, USA). Samples were centrifuged at $4^{\circ} \mathrm{C}$ for $35 \mathrm{~min}$ at $160000 \mathrm{~g}$ using a SW41 rotor in a Beckman L-880M Ultracentrifuge with low acceleration and low brakes. The synaptosome fraction which was distinguishable as a cloudy band at the interface of 0.32 and $1.2 \mathrm{M}$ sucrose was removed and $500 \mu \mathrm{l}$ aliquots of supernatant $(0.32 \mathrm{~m}$ sucrose layer $)$ and the lower face $(1.2 \mathrm{M}$ sucrose layer) were also collected in order to confirm the purity of the fractions. The synaptosomal fraction was diluted in $10 \mathrm{ml}$ of $0.32 \mathrm{~m}$ sucrose, mixed and centrifuged again at $4^{\circ} \mathrm{C}$ for $30 \mathrm{~min}$ at $160000 \mathrm{~g}(33000 \mathrm{rpm})$ in an SW41 rotor. The final fraction was resuspended in $500 \mu l$ of $0.32 \mathrm{M}$ sucrose supplemented with protease inhibitors and $1 \mathrm{~mm}$ DTT as an antioxidant. Samples were frozen in small volumes at $-80^{\circ} \mathrm{C}$. According to Hajos, the synaptosomal fraction is highly enriched in pre- and postsynaptic elements ( $90 \%$ of all elements) compared with other methods for isolating synaptosomes (86). Protein levels in fractions were measured using the Bradford protocol.

\section{Preparation of DRMs}

DRMs from WT and $\mathrm{HD}^{140 \mathrm{Q} / 140 \mathrm{Q}}$ cortical neurons at 8 DIV were isolated in Brij-98-containing buffer by ultracentrifugation in a linear sucrose gradient $(5-35 \%)$ as described before (15). Cultured primary neurons $\left(60 \times 10^{6}\right.$ cells per sample) were washed twice in DEB buffer containing $10 \mathrm{~mm}$ Tris, $150 \mathrm{~mm} \mathrm{NaCl}, \mathrm{pH} 7.5,0.1 \mu \mathrm{g} / \mathrm{ml}$ pepstatin A and EDTAfree complete protease inhibitor (Roche Diagnostics GmbH, Indianapolis, IN, USA), then cells were harvested on ice in the cold room with TEB buffer (DEB buffer supplemented with $\left.0.5 \% \mathrm{Brij}^{\circledR} 98\right)$. A linear sucrose gradient $(5-35 \%)$ was layered on top of cell lysate $(4 \mathrm{mg}$ of protein in $2 \mathrm{ml}$ total volume) in a 13-ml ultracentrifuge tube. Gradients were then centrifuged for $24 \mathrm{~h}$ at $39000 \mathrm{rpm}\left(2^{\circ} \mathrm{C}\right)$ using an SW 41 rotor with low acceleration and no brakes. The next day, $1-\mathrm{ml}$ fractions were collected from the top of the tubes, obtaining 12 total fractions. These were further centrifuged at 55 $000 \mathrm{rpm}$ using a Ti 70.1 rotor for $45 \mathrm{~min}$; the pellet was resuspended in GAL-4 buffer (50 mm Tris, pH 7.4, 1\% NP-40, $5 \mathrm{~mm}$ EDTA plus protease inhibitors). Protein content was measured by Bradford assay. Equal volumes of the fractions were loaded for SDS-PAGE and western blot analysis. G $\alpha$ q was used as a raft marker, as shown before (15), DRM fractions 5-6 are enriched with lipid rafts.

\section{Statistical analysis}

Statistical analyses were performed using Student's $t$-test and $P$ values are indicated in the results and in the figure legends. To determine the differences in the percent of neurons with varicosities, a two-tailed $\chi^{2}$ test was performed using the raw values (GraphPad Prism). Measurements are expressed as mean \pm standard deviation (SD), or as indicated in the related section.

\section{SUPPLEMENTARY MATERIAL}

Supplementary Material is available at $H M G$ online.

\section{ACKNOWLEDGEMENTS}

We thank Karlotta Fitch of the Massachusetts Alzheimer's Disease Research Center for helping with the human tissue and Dr Charles Vanderburg for his assistance on confocal microscope images for the triple staining.

Conflict of Interest statement. None declared.

\section{FUNDING}

This study was supported by fellowships from the Hereditary Disease Foundation to A.V. and X.L., Fundacion Mexico en Harvard A.C. to A.V., and CHDI and HDSA Foundations and NIH-NINDS NS74381 to M.D.

\section{REFERENCES}

1. Valencia, A. and Moran, J. (2004) Reactive oxygen species induce different cell death mechanisms in cultured neurons. Free Radic. Biol. Med., 36, 1112-1125.

2. Ma, L. and Nicholson, L.F. (2004) Expression of the receptor for advanced glycation end products in Huntington's disease caudate nucleus. Brain Res., 1018, 10-17. 
3. Stoy, N., Mackay, G.M., Forrest, C.M., Christofides, J., Egerton, M., Stone, T.W. and Darlington, L.G. (2005) Tryptophan metabolism and oxidative stress in patients with Huntington's disease. J. Neurochem., 93, $611-623$.

4. Chen, C.M., Wu, Y.R., Cheng, M.L., Liu, J.L., Lee, Y.M., Lee, P.W., Soong, B.W. and Chiu, D.T. (2007) Increased oxidative damage and mitochondrial abnormalities in the peripheral blood of Huntington's disease patients. Biochem. Biophys. Res. Commun., 359, 335-340.

5. del Hoyo, P., Garcia-Redondo, A., de Bustos, F., Molina, J.A., Sayed, Y., Alonso-Navarro, H., Caballero, L., Arenas, J. and Jimenez-Jimenez, F.J. (2006) Oxidative stress in skin fibroblasts cultures of patients with Huntington's disease. Neurochem. Res., 31, 1103-1109.

6. Klepac, N., Relja, M., Klepac, R., Hecimovic, S., Babic, T. and Trkulja, V. (2007) Oxidative stress parameters in plasma of Huntington's disease patients, asymptomatic Huntington's disease gene carriers and healthy subjects: a cross-sectional study. J. Neurol., 254, 1676-1683.

7. De Luca, G., Russo, M.T., Degan, P., Tiveron, C., Zijno, A., Meccia, E., Ventura, I., Mattei, E., Nakabeppu, Y., Crescenzi, M. et al. (2008) A role for oxidized DNA precursors in Huntington's disease-like striatal neurodegeneration. PLoS Genet., 4, e1000266.

8. Maksimovic, I.D., Jovanovic, M.D., Colic, M., Mihajlovic, R., Micic, D., Selakovic, V., Ninkovic, M., Malicevic, Z., Rusic-Stojiljkovic, M. and Jovicic, A. (2001) Oxidative damage and metabolic dysfunction in experimental Huntington's disease: selective vulnerability of the striatum and hippocampus. Vojnosanit. Pregl., 58, 237-242.

9. Perez-Severiano, F., Rios, C. and Segovia, J. (2000) Striatal oxidative damage parallels the expression of a neurological phenotype in mice transgenic for the mutation of Huntington's disease. Brain Res., 862, 234-237.

10. Bogdanov, M.B., Andreassen, O.A., Dedeoglu, A., Ferrante, R.J. and Beal, M.F. (2001) Increased oxidative damage to DNA in a transgenic mouse model of Huntington's disease. J. Neurochem., 79, 1246-1249.

11. Schilling, G., Coonfield, M.L., Ross, C.A. and Borchelt, D.R. (2001) Coenzyme Q10 and remacemide hydrochloride ameliorate motor deficits in a Huntington's disease transgenic mouse model. Neurosci. Lett., 315, $149-153$.

12. Stack, E.C., Smith, K.M., Ryu, H., Cormier, K., Chen, M., Hagerty, S.W., Del Signore, S.J., Cudkowicz, M.E., Friedlander, R.M. and Ferrante, R.J. (2006) Combination therapy using minocycline and coenzyme Q10 in R6/ 2 transgenic Huntington's disease mice. Biochim. Biophys. Acta, 1762, $373-380$.

13. Stack, E.C., Matson, W.R. and Ferrante, R.J. (2008) Evidence of oxidant damage in Huntington's disease: translational strategies using antioxidants. Ann. N. Y. Acad. Sci., 1147, 79-92.

14. Guidetti, P., Charles, V., Chen, E.Y., Reddy, P.H., Kordower, J.H., Whetsell, W.O. Jr, Schwarcz, R. and Tagle, D.A. (2001) Early degenerative changes in transgenic mice expressing mutant huntingtin involve dendritic abnormalities but no impairment of mitochondrial energy production. Exp. Neurol., 169, 340-350.

15. Valencia, A., Reeves, P.B., Sapp, E., Li, X., Alexander, J., Kegel, K.B., Chase, K., Aronin, N. and DiFiglia, M. (2010) Mutant huntingtin and glycogen synthase kinase 3-beta accumulate in neuronal lipid rafts of a presymptomatic knock-in mouse model of Huntington's disease. J. Neurosci. Res., 88, 179-190.

16. Koshkin, V. and Pick, E. (1993) Generation of superoxide by purified and relipidated cytochrome b559 in the absence of cytosolic activators. FEBS Lett., 327, 57-62.

17. Groemping, Y. and Rittinger, K. (2005) Activation and assembly of the NADPH oxidase: a structural perspective. Biochem. J., 386, 401-416.

18. Bedard, K. and Krause, K.H. (2007) The NOX family of ROS-generating NADPH oxidases: physiology and pathophysiology. Physiol. Rev., 87, $245-313$.

19. Lam, G.Y., Huang, J. and Brumell, J.H. (2010) The many roles of NOX2 NADPH oxidase-derived ROS in immunity. Semin. Immunopathol., 32 , $415-430$.

20. Shao, D., Segal, A.W. and Dekker, L.V. (2003) Lipid rafts determine efficiency of NADPH oxidase activation in neutrophils. FEBS Lett., 550, 101-106.

21. Faurschou, M. and Borregaard, N. (2003) Neutrophil granules and secretory vesicles in inflammation. Microbes Infect., 5, 1317-1327.

22. Sorce, S., Schiavone, S., Tucci, P., Colaianna, M., Jaquet, V., Cuomo, V., Dubois-Dauphin, M., Trabace, L. and Krause, K.H. (2010) The NADPH oxidase NOX2 controls glutamate release: a novel mechanism involved in psychosis-like ketamine responses. J. Neurosci., 30, 11317-11325.

23. Samhan-Arias, A.K., Garcia-Bereguiain, M.A., Martin-Romero, F.J. and Gutierrez-Merino, C. (2009) Clustering of plasma membrane-bound cytochrome b5 reductase within 'lipid raft' microdomains of the neuronal plasma membrane. Mol. Cell. Neurosci., 40, 14-26.

24. Vilhardt, F. and van Deurs, B. (2004) The phagocyte NADPH oxidase depends on cholesterol-enriched membrane microdomains for assembly. Embo. J., 23, 739-748.

25. Suzukawa, K., Miura, K., Mitsushita, J., Resau, J., Hirose, K., Crystal, R. and Kamata, T. (2000) Nerve growth factor-induced neuronal differentiation requires generation of Rac1-regulated reactive oxygen species. J. Biol. Chem., 275, 13175-13178.

26. Ibi, M., Katsuyama, M., Fan, C., Iwata, K., Nishinaka, T., Yokoyama, T. and Yabe-Nishimura, C. (2006) NOX1/NADPH oxidase negatively regulates nerve growth factor-induced neurite outgrowth. Free Radic. Biol. Med., 40, 1785-1795.

27. Munnamalai, V. and Suter, D.M. (2009) Reactive oxygen species regulate F-actin dynamics in neuronal growth cones and neurite outgrowth. J. Neurochem., 108, 644-661.

28. DeCoursey, T.E. (2008) Voltage-gated proton channels. Cell Mol. Life Sci., 65, 2554-2573.

29. Dugan, L.L., Ali, S.S., Shekhtman, G., Roberts, A.J., Lucero, J., Quick, K.L. and Behrens, M.M. (2009) IL-6 mediated degeneration of forebrain GABAergic interneurons and cognitive impairment in aged mice through activation of neuronal NADPH oxidase. PLoS One, 4, e5518.

30. Brennan, A.M., Suh, S.W., Won, S.J., Narasimhan, P., Kauppinen, T.M., Lee, H., Edling, Y., Chan, P.H. and Swanson, R.A. (2009) NADPH oxidase is the primary source of superoxide induced by NMDA receptor activation. Nat. Neurosci., 12, 857-863.

31. Ha, J.S., Lee, J.E., Lee, J.R., Lee, C.S., Maeng, J.S., Bae, Y.S., Kwon, K.S. and Park, S.S. (2010) Nox4-dependent $\mathrm{H}_{2} \mathrm{O}_{2}$ production contributes to chronic glutamate toxicity in primary cortical neurons. Exp. Cell Res., 316, 1651-1661

32. Chen, H., Yoshioka, H., Kim, G.S., Jung, J.E., Okami, N., Sakata, H., Maier, C.M., Narasimhan, P., Goeders, C.E. and Chan, P.H. (2011) Oxidative stress in ischemic brain damage: mechanisms of cell death and potential molecular targets for neuroprotection. Antioxid. Redox Signal., 14, 1505-1517.

33. Yoshioka, H., Niizuma, K., Katsu, M., Okami, N., Sakata, H., Kim, G.S., Narasimhan, P. and Chan, P.H. (2011) NADPH oxidase mediates striatal neuronal injury after transient global cerebral ischemia. J. Cereb. Blood Flow Metab., 31, 868-880.

34. Kannan, K.B., Barlos, D. and Hauser, C.J. (2007) Free cholesterol alters lipid raft structure and function regulating neutrophil $\mathrm{Ca}^{2+}$ entry and respiratory burst: correlations with calcium channel raft trafficking J. Immunol., 178, 5253-5261.

35. Kleinschnitz, C., Grund, H., Wingler, K., Armitage, M.E., Jones, E., Mittal, M., Barit, D., Schwarz, T., Geis, C., Kraft, P. et al. (2010) Post-stroke inhibition of induced NADPH oxidase type 4 prevents oxidative stress and neurodegeneration. PLoS Biol., 8, e1000479.

36. Murotomi, K., Takagi, N., Takeo, S. and Tanonaka, K. (2011) NADPH oxidase-mediated oxidative damage to proteins in the postsynaptic density after transient cerebral ischemia and reperfusion. Mol. Cell Neurosci., 46 , 681-688.

37. Pestana, R.R., Kinjo, E.R., Hernandes, M.S. and Britto, L.R. (2010) Reactive oxygen species generated by NADPH oxidase are involved in neurodegeneration in the pilocarpine model of temporal lobe epilepsy. Neurosci. Lett., 484, 187-191.

38. Maldonado, P.D., Molina-Jijon, E., Villeda-Hernandez, J., Galvan-Arzate, S., Santamaria, A. and Pedraza-Chaverri, J. (2010) NAD(P)H oxidase contributes to neurotoxicity in an excitotoxic/prooxidant model of Huntington's disease in rats: protective role of apocynin. J. Neurosci. Res., 88, 620-629.

39. Anantharam, V., Kaul, S., Song, C., Kanthasamy, A. and Kanthasamy, A.G. (2007) Pharmacological inhibition of neuronal NADPH oxidase protects against 1-methyl-4-phenylpyridinium (MPP+)-induced oxidative stress and apoptosis in mesencephalic dopaminergic neuronal cells. Neurotoxicology, 28, 988-997.

40. Bertoni, A., Giuliano, P., Galgani, M., Rotoli, D., Ulianich, L., Adornetto, A., Santillo, M.R., Porcellini, A. and Avvedimento, V.E. (2010) Early and late events induced by PolyQ-expanded proteins: identification of a 
common pathogenic property of polyQ-expanded proteins. J. Biol. Chem., 286, 4727-4741.

41. Shpungin, S., Dotan, I., Abo, A. and Pick, E. (1989) Activation of the superoxide forming NADPH oxidase in a cell-free system by sodium dodecyl sulfate. Absolute lipid dependence of the solubilized enzyme. J. Biol. Chem., 264, 9195-9203.

42. Menalled, L.B., Sison, J.D., Dragatsis, I., Zeitlin, S. and Chesselet, M.F. (2003) Time course of early motor and neuropathological anomalies in a knock-in mouse model of Huntington's disease with 140 CAG repeats. J. Comp. Neurol., 465, 11-26.

43. Hickey, M.A., Kosmalska, A., Enayati, J., Cohen, R., Zeitlin, S., Levine, M.S. and Chesselet, M.F. (2008) Extensive early motor and non-motor behavioral deficits are followed by striatal neuronal loss in knock-in Huntington's disease mice. Neuroscience, 157, 280-295.

44. Valencia, A., Sapp, E., Reeves, P.B., Alexander, J., Masso, N., Li, X., Kegel, K.B. and DiFiglia, M. (2012) Reagents that block neuronal death from Huntington's disease also curb oxidative stress. Neuroreport, 23 $10-15$.

45. Li, X., Valencia, A., Sapp, E., Masso, N., Alexander, J., Reeves, P., Kegel, K.B., Aronin, N. and Difiglia, M. (2010) Aberrant Rab11-dependent trafficking of the neuronal glutamate transporter EAAC1 causes oxidative stress and cell death in Huntington's disease. J. Neurosci., 30, 4552 4561.

46. O’Donnell, B.V., Tew, D.G., Jones, O.T. and England, P.J. (1993) Studies on the inhibitory mechanism of iodonium compounds with special reference to neutrophil NADPH oxidase. Biochem. J., $290(\mathrm{Pt} 1), 41-49$.

47. Stolk, J., Hiltermann, T.J., Dijkman, J.H. and Verhoeven, A.J. (1994) Characteristics of the inhibition of NADPH oxidase activation in neutrophils by apocynin, a methoxy-substituted catechol. Am. J. Respir. Cell Mol. Biol., 11, 95-102.

48. Gerstner, B., DeSilva, T.M., Genz, K., Armstrong, A., Brehmer, F., Neve, R.L., Felderhoff-Mueser, U., Volpe, J.J. and Rosenberg, P.A. (2008) Hyperoxia causes maturation-dependent cell death in the developing white matter. J. Neurosci., 28, 1236-1245.

49. Kirkland, R.A., Saavedra, G.M. and Franklin, J.L. (2007) Rapid activation of antioxidant defenses by nerve growth factor suppresses reactive oxygen species during neuronal apoptosis: evidence for a role in cytochrome c redistribution. J. Neurosci., 27, 11315-11326.

50. Perez-Severiano, F., Santamaria, A., Pedraza-Chaverri, J., Medina-Campos, O.N., Rios, C. and Segovia, J. (2004) Increased formation of reactive oxygen species, but no changes in glutathione peroxidase activity, in striata of mice transgenic for the Huntington's disease mutation. Neurochem. Res., 29, 729-733.

51. Vaughn, A.E. and Deshmukh, M. (2008) Glucose metabolism inhibits apoptosis in neurons and cancer cells by redox inactivation of cytochrome c. Nat. Cell Biol., 10, 1477-1483.

52. Lee, M.S., Kwon, Y.T., Li, M., Peng, J., Friedlander, R.M. and Tsai, L.H. (2000) Neurotoxicity induces cleavage of p 35 to p 25 by calpain. Nature, 405, 360-364.

53. Ricart, K.C. and Fiszman, M.L. (2001) Hydrogen peroxide-induced neurotoxicity in cultured cortical cells grown in serum-free and serum-containing media. Neurochem. Res., 26, 801-808.

54. Altenhöfer, S., Kleikers, P.W., Radermacher, K.A., Scheurer, P., Rob Hermans, J.J., Schiffers, P., Ho, H., Wingler, K. and Schmidt, H.H. (2012) The NOX toolbox: validating the role of NADPH oxidases in physiology and disease. Cell Mol. Life Sci., 69, 2327-2343.

55. Serrano, F., Kolluri, N.S., Wientjes, F.B., Card, J.P. and Klann, E. (2003) NADPH oxidase immunoreactivity in the mouse brain. Brain Res., 988, 193-198.

56. Tejada-Simon, M.V., Serrano, F., Villasana, L.E., Kanterewicz, B.I., Wu, G.Y., Quinn, M.T. and Klann, E. (2005) Synaptic localization of a functional NADPH oxidase in the mouse hippocampus. Mol. Cell Neurosci., 29, 97-106.

57. Rao Malla, R., Raghu, H. and Rao, J.S. (2010) Regulation of NADPH oxidase (Nox2) by lipid rafts in breast carcinoma cells. Int. J. Oncol., 37, $1483-1493$

58. Zhang, A.Y., Yi, F., Zhang, G., Gulbins, E. and Li, P.L. (2006) Lipid raft clustering and redox signaling platform formation in coronary arterial endothelial cells. Hypertension, 47, 74-80.

59. Ushio-Fukai, M. (2007) VEGF signaling through NADPH oxidase-derived ROS. Antioxid. Redox Signal., 9, 731-739.

60. Kawakami-Mori, F., Shimosawa, T., Mu, S., Wang, H., Ogura, S., Yatomi, Y. and Fujita, T. (2012) NADPH oxidase-mediated Rac1 GTP activity is necessary for nongenomic actions of the mineralocorticoid receptor in the CA1 region of the rat hippocampus. Am. J. Physiol. Endocrinol. Metab., 302, E425-E432.

61. Choi, D.H., Cristovao, A.C., Guhathakurta, S., Lee, J., Joh, T.H., Beal, M.F. and Kim, Y.S. (2012) NADPH oxidase 1-mediated oxidative stress leads to dopamine neuron death in Parkinson's disease. Antioxid. Redox Signal., 16, 1033-1045.

62. Miyano, K. and Sumimoto, H. (2012) Assessment of the role for rho family GTPases in NADPH oxidase activation. Methods Mol. Biol., 827, 195-212.

63. Pollock, J.D., Williams, D.A., Gifford, M.A., Li, L.L., Du, X., Fisherman, J., Orkin, S.H., Doerschuk, C.M. and Dinauer, M.C. (1995) Mouse model of X-linked chronic granulomatous disease, an inherited defect in phagocyte superoxide production. Nat. Genet., 9, 202-209.

64. Martinez, A., Portero-Otin, M., Pamplona, R. and Ferrer, I. (2010) Protein targets of oxidative damage in human neurodegenerative diseases with abnormal protein aggregates. Brain Pathol., 20, 281-297.

65. Zaidi, A., Fernandes, D., Bean, J.L. and Michaelis, M.L. (2009) Effects of paraquat-induced oxidative stress on the neuronal plasma membrane $\mathrm{Ca}(2+)$-ATPase. Free Radic. Biol. Med., 47, 1507-1514.

66. Demaurex, N. and Scorrano, L. (2009) Reactive oxygen species are NOXious for neurons. Nat. Neurosci., 12, 819-820.

67. Dyer, R.B. and McMurray, C.T. (2001) Mutant protein in Huntington disease is resistant to proteolysis in affected brain. Nat. Genet., 29, 270-278

68. Saudou, F., Finkbeiner, S., Devys, D. and Greenberg, M.E. (1998) Huntingtin acts in the nucleus to induce apoptosis but death does not correlate with the formation of intranuclear inclusions. Cell, 95, 55-66.

69. DiFiglia, M., Sapp, E., Chase, K.O., Davies, S.W., Bates, G.P., Vonsattel, J.P. and Aronin, N. (1997) Aggregation of huntingtin in neuronal intranuclear inclusions and dystrophic neurites in brain. Science, 277, 1990-1993.

70. Laforet, G.A., Sapp, E., Chase, K., McIntyre, C., Boyce, F.M., Campbell, M., Cadigan, B.A., Warzecki, L., Tagle, D.A., Reddy, P.H. et al. (2001) Changes in cortical and striatal neurons predict behavioral and electrophysiological abnormalities in a transgenic murine model of Huntington's disease. J. Neurosci., 21, 9112-9123.

71. Cummings, D.M., Andre, V.M., Uzgil, B.O., Gee, S.M., Fisher, Y.E., Cepeda, C. and Levine, M.S. (2009) Alterations in cortical excitation and inhibition in genetic mouse models of Huntington's disease. J. Neurosci., 29, 10371-10386.

72. Roediger, B. and Armati, P.J. (2003) Oxidative stress induces axonal beading in cultured human brain tissue. Neurobiol. Dis., 13, 222-229.

73. Larsen, K.E., Fon, E.A., Hastings, T.G., Edwards, R.H. and Sulzer, D. (2002) Methamphetamine-induced degeneration of dopaminergic neurons involves autophagy and upregulation of dopamine synthesis. J. Neurosci., 22, 8951-8960.

74. Richards, P., Didszun, C., Campesan, S., Simpson, A., Horley, B., Young, K.W., Glynn, P., Cain, K., Kyriacou, C.P., Giorgini, F. et al. (2011) Dendritic spine loss and neurodegeneration is rescued by Rab11 in models of Huntington's disease. Cell Death Differ., 18, 191-200.

75. Sapp, E., Penney, J., Young, A., Aronin, N., Vonsattel, J.P. and DiFiglia, M. (1999) Axonal transport of N-terminal huntingtin suggests early pathology of corticostriatal projections in Huntington disease. J. Neuropathol. Exp. Neurol., 58, 165-173.

76. Dohi, K., Ohtaki, H., Nakamachi, T., Yofu, S., Satoh, K., Miyamoto, K., Song, D., Tsunawaki, S., Shioda, S. and Aruga, T. (2010) Gp91phox (NOX2) in classically activated microglia exacerbates traumatic brain injury. J. Neuroinflammation, 7, 41.

77. Kim, D., You, B., Jo, E.K., Han, S.K., Simon, M.I. and Lee, S.J. (2010) NADPH oxidase 2-derived reactive oxygen species in spinal cord microglia contribute to peripheral nerve injury-induced neuropathic pain. Proc. Natl Acad. Sci. USA, 107, 14851-14856.

78. Sapp, E., Kegel, K.B., Aronin, N., Hashikawa, T., Uchiyama, Y., Tohyama, K., Bhide, P.G., Vonsattel, J.P. and DiFiglia, M. (2001) Early and progressive accumulation of reactive microglia in the Huntington disease brain. J. Neuropathol. Exp. Neurol., 60, 161-172.

79. Dusi, S. and Rossi, F. (1993) Activation of NADPH oxidase of human neutrophils involves the phosphorylation and the translocation of cytosolic p67phox. Biochem. J., 296 (Pt 2), 367-371.

80. Kaltenbach, L.S., Romero, E., Becklin, R.R., Chettier, R., Bell, R. Phansalkar, A., Strand, A., Torcassi, C., Savage, J., Hurlburt, A. et al. (2007) Huntingtin interacting proteins are genetic modifiers of neurodegeneration. PLoS Genet., 3, e82. 
81. Kegel, K.B., Sapp, E., Alexander, J., Valencia, A., Reeves, P., Li, X., Masso, N., Sobin, L., Aronin, N. and DiFiglia, M. (2009) Polyglutamine expansion in huntingtin alters its interaction with phospholipids. J. Neurochem., 110, 1585-1597.

82. Hersch, S.M., Gevorkian, S., Marder, K., Moskowitz, C., Feigin, A., Cox, M., Como, P., Zimmerman, C., Lin, M., Zhang, L. et al. (2006) Creatine in Huntington disease is safe, tolerable, bioavailable in brain and reduces serum $8 \mathrm{OH2}$ 'dG. Neurology, 66, 250-252.

83. Valencia, A. and Moran, J. (2001) Role of oxidative stress in the apoptotic cell death of cultured cerebellar granule neurons. J. Neurosci. Res., 64, 284-297.
84. Archer, S.L., Reeve, H.L., Michelakis, E., Puttagunta, L., Waite, R., Nelson, D.P., Dinauer, M.C. and Weir, E.K. (1999) O2 sensing is preserved in mice lacking the gp91 phox subunit of NADPH oxidase. Proc. Natl Acad. Sci. USA, 96, 7944-7949.

85. DiFiglia, M., Sapp, E., Chase, K., Schwarz, C., Meloni, A., Young, C., Martin, E., Vonsattel, J.P., Carraway, R., Reeves, S.A. et al. (1995) Huntingtin is a cytoplasmic protein associated with vesicles in human and rat brain neurons. Neuron, 14, 1075-1081.

86. Hajos, F. (1975) An improved method for the preparation of synaptosomal fractions in high purity. Brain Res., 93, 485-489. 